\title{
Effects of Prefrontal Cortical Inactivation on Neural Activity in the Ventral Tegmental Area
}

\author{
Yong Sang Jo, ${ }^{1}$ Jane Lee, ${ }^{1}$ and Sheri J.Y. Mizumori ${ }^{1,2}$ \\ ${ }^{1}$ Department of Psychology, University of Washington, Seattle, Washington 98195, and ${ }^{2}$ Neurobiology and Behavior Program, University of Washington, \\ Seattle, Washington 98195
}

Dopamine (DA) cells have been suggested to signal discrepancies between expected and actual rewards in reinforcement learning. DA cells in the ventral tegmental area (VTA) receive direct projections from the medial prefrontal cortex (mPFC), a structure known to be one of the brain areas that represents expected future rewards. To investigate whether the mPFC contributes to generating reward prediction error signals of DA cells, we recorded VTA cells from rats foraging for different amounts of reward in a spatial working memory task. Our results showed that DA cells initially responded after the acquisition of rewards, but over training, they exhibited phasic responses when rats detected sensory cues originating from the rewards before obtaining them. We also observed two separate groups of non-DA cells

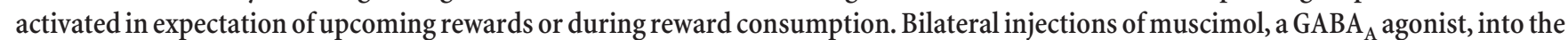
mPFC significantly decreased the non-DA activity that encoded reward expectation. By contrast, the same manipulation of the mPFC elevated DA responses to reward-predicting cues. However, neither DA nor non-DA responses elicited after reward acquisition were affected by $\mathrm{mPFC}$ inactivation. These results suggest that the mPFC provides information about expected rewards to the VTA, and its functional loss elevates DA responses to reward-predicting cues by altering expectations about forthcoming rewards.

\section{Introduction}

Dopamine (DA) cells in the ventral tegmental area (VTA) are involved in reinforcement learning and motivation (Wise, 2004; Fields et al., 2007). DA cells are thought to encode reward prediction errors by exhibiting phasic responses to unexpected rewards and reward-predicting cues, but not to fully expected rewards (Montague et al., 1996; Schultz et al., 1997; Fiorillo et al., 2003; Pan et al., 2005; Day et al., 2007; Roesch et al., 2007; Clark et al., 2010). To compute these signals, DA cells need to integrate various kinds of information regarding sensory cues, expected outcomes, and perceived rewards. Prior research suggests that the error signaling in freely behaving rodents is altered by experimental manipulation of two major afferent structures to the VTA: (1) the pedunculopontine tegmental nucleus, which is thought to convey cue-related sensory information (Pan and Hyland, 2005), and (2) the orbitofrontal cortex, which conveys reward expectancy information (Takahashi et al., 2011). However, little is known about how the medial prefrontal cortex (mPFC) contributes to reward prediction errors even though it provides the greatest excitatory cortical input to the VTA (Carr and Sesack, 2000; Geisler and Wise, 2008).

The PFC has long been implicated in maintaining neural representations for working memory and for signaling future out-

\footnotetext{
Received Jan. 10, 2013; revised March 8, 2013; accepted March 31, 2013.

Author contributions: Y.S.J., J.L., and S.J.Y.M. designed research; Y.S.J. and J.L. performed research; Y.S.J., J.L., and S.J.Y.M. analyzed data; Y.S.J., J.L., and S.J.Y.M. wrote the paper.

This work was supported by National Institute of Mental Health Grant MH 58755 to S.J.Y.M. We thank Geoffrey

Schoenbaum and Yuji Takahashi for sharing their expertise on dopamine cell identification methods.

Correspondence should be addressed to Sheri J.Y. Mizumori at the above address. E-mail: mizumori@uw.edu.

DOI:10.1523/JNEUROSCI.0118-13.2013

Copyright $\odot 2013$ the authors $\quad 0270-6474 / 13 / 338159-13 \$ 15.00 / 0$
}

comes of goal-directed behavior (Goldman-Rakic, 1995; Fuster, 1997; Miller and Cohen, 2001). Electrophysiological evidence indicates that individual neurons in the MPFC respond in expectation of upcoming rewards (Pratt and Mizumori, 2001; Miyazaki et al., 2004; Sul et al., 2010). Thus, it is possible that the representation of expected rewards in the mPFC makes important contributions to computations of reward prediction errors by DA cells. To test this idea, we recorded VTA cells from rats foraging in a mPFC-dependent spatial working memory task that involved learning locations associated with different amounts of reward. We identified prediction error signals by DA cells and then tested whether these signals were significantly altered after bilateral inactivations of the mPFC. Based on the previous finding that $\mathrm{mPFC}$ neurons showed anticipatory changes in firing before reward acquisition in the current foraging task (Pratt and Mizumori, 2001), we hypothesized that mPFC inactivation would selectively impact DA responses to reward-predicting stimuli more than to actual rewards. In addition, a recent report suggests that GABA neurons in the VTA convey reward expectation signals to neighboring DA cells (Cohen et al., 2012). Thus, we also determined the effects of mPFC inactivation on non-DA cells. The combined results of this study could provide a better understanding of the neural mechanism through which the MPFC regulates the midbrain DA system.

\section{Materials and Methods}

Subjects. Six male Long-Evans rats (340-360 g; Simonson Laboratories) were housed individually in Plexiglas cages. The rats were maintained on a $12 \mathrm{~h} \mathrm{light/dark} \mathrm{cycle} \mathrm{(lights} \mathrm{on} \mathrm{at} \mathrm{7:00} \mathrm{A.M.)} \mathrm{and} \mathrm{all} \mathrm{behavioral} \mathrm{exper-}$ iments were performed during the light phase of the cycle. Each rat was allowed access to water ad libitum and food-deprived to $80 \%$ of its ad libitum feeding weight. All animal care and use were conducted in accor- 
dance with University of Washington's Institutional Animal Care and Use Committee guidelines.

Differential-reward, spatial memory task. Detailed information of the apparatus and training procedures can be found in previous studies (Pratt and Mizumori, 2001; Puryear et al., 2010; Norton et al., 2011). Briefly, rats were familiarized with an elevated eight-arm maze (79 $\mathrm{cm}$ from the floor; Fig. $1 \mathrm{~A}$ ) and allowed to freely forage chocolate milk scattered on black Plexiglas arms $(58 \times 5.5 \mathrm{~cm}$ each $)$ that radiated from a circular central platform $(19.5 \mathrm{~cm}$ in diameter) for 1-2 weeks. Each maze arm was hinged such that its proximal end to the central platform could be raised and lowered by remote control from an adjacent room. The maze was surrounded by black curtains decorated with several visual cues. Once the rat consistently moved about and consumed rewards for $30 \mathrm{~min}$, the training for a spatial memory task started.

While a rat was constrained on the central platform by lowering all maze arms (Fig. 1A), food cups located at the end of the maze arms were baited with either a large $(0.3 \mathrm{ml})$ or small $(0.05 \mathrm{ml})$ amount of chocolate milk on alternating arms (e.g., large rewards on even-numbered arms and small rewards on odd-numbered arms). Subsequent training trials consisted of a study and a test phase. During the study phase of each trial, four of the eight arms (two largereward and two small-reward arms) were randomly selected and presented individually. After presentation of the fourth arm, the test phase began upon making all maze arms accessible at once. The rat was required to collect the remaining rewards from the four arms not presented during the study phase. Revisits (i.e., when animals went at least halfway down a maze arm) to previously visited arms within a trial were defined as errors. These errors were further divided into two subtypes, acrossphase errors and within-phase errors, based on whether an error was caused by re-entering any arm that had been visited during the study phase and test phase, respectively. When the animal returned to the central platform after visiting all eight arms, it was confined to the platform for an intertrial interval (ITI) of 2 min. Meanwhile, all food cups were baited again and 10 trials were given per day. The locations of differentially rewarded arms were held constant in each rat throughout training but counterbalanced across rats. After rats made an average of one or fewer errors on a training day, rats underwent a surgical procedure for the implantation of recording electrodes.

Surgery. Recording tetrodes were constructed from $20 \mu \mathrm{m}$ lacquer-coated tungsten wires (California Fine Wire) and mounted on an array of six independently adjustable microdrives (Neuralynx). Tetrode tips were goldplated to reduce impedance to $0.2-0.4 \mathrm{M} \Omega$ (tested at $1 \mathrm{kHz}$ ). Each rat was placed in an induction chamber and deeply anesthetized under isoflurane (4\% mix with oxygen at a flow rate of $1 \mathrm{~L} / \mathrm{min}$ ). While unconscious, the animal was placed in a stereotaxic instrument (David Kopf Instruments) and anesthesia was maintained

B
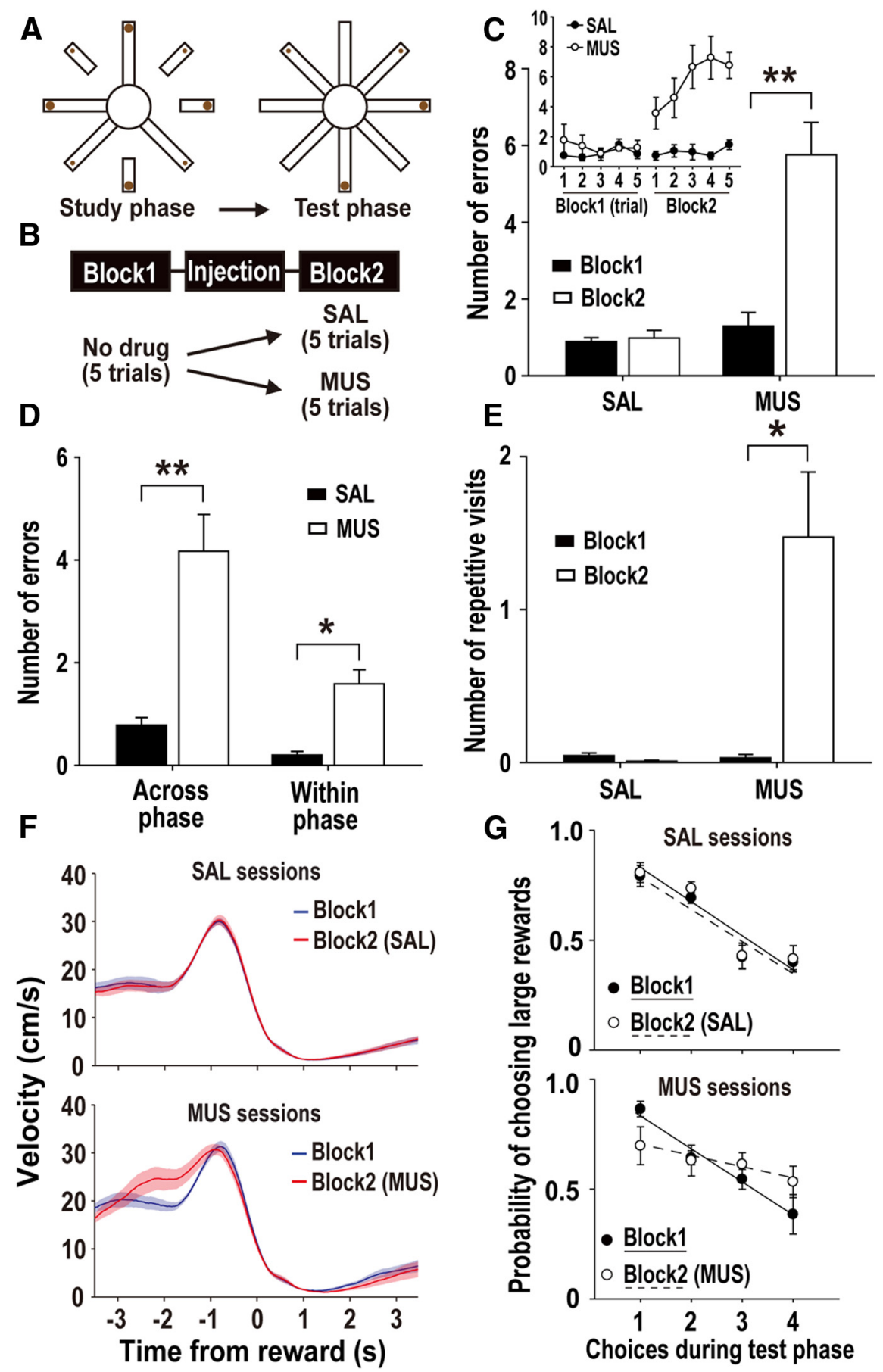

Figure 1. Behavioral performance. $A$, Schematic illustration of the spatial working memory task. Each trial began with the study phase in which four randomly chosen arms were individually presented. Then, all eight arms were presented after the fourth visit. During this test phase, rats were required to forage for the remaining chocolate milk reward. $\boldsymbol{B}$, Experimental design. Rats were tested without drugs in the first block of five trials. After either SAL or MUS was injected into the mPFC, the second testing block was given. $C$, Average number of errors in the spatial working memory task. Inset shows the breakdown of errors per trial. $D$, Average number of across-phase and within-phase errors made by rats injected with each drug. $E$, Average number of repetitive visits to the same arms. A repetitive visit was counted when rats entered the same arms in an A-B-A fashion during the test phase. $F$, Average velocity traces around the time of reward acquisition $\left(t_{0}\right)$. The shaded regions indicate SEM. $G$, Probability of choosing large-reward arms during the first four choices of the test phase. The solid and dotted lines indicate linear correlations for the corresponding blocks. ${ }^{*} p<0.05,{ }^{* *} p<0.01$.

throughout surgery by isoflurane $(1 \sim 2.5 \%)$ delivered via a nosecone. The skull was exposed and adjusted to place bregma and lambda on the same horizontal plane. After small burr holes were drilled, two 25 gauge cannulas were bilaterally located into the $\mathrm{mPFC}$ ( $3 \mathrm{~mm}$ anterior, $0.7 \mathrm{~mm}$ lateral, and $4.2 \mathrm{~mm}$ ventral to bregma). Then a microdrive array was 
unilaterally implanted so that the tetrodes could be placed dorsal to the VTA in one hemisphere $(5.3 \mathrm{~mm}$ posterior, $0.8 \mathrm{~mm}$ lateral to bregma, and $7.0 \mathrm{~mm}$ ventral from the dural surface). The cannulas and microdrive array were secured in place with anchoring screws and dental cement. A 33 gauge dummy cannula was inserted into each guide to prevent clogging. Rats were allowed to recover for $7 \mathrm{~d}$, during which they were handled daily.

Intracranial microinjection. Muscimol (MUS, $1 \mu \mathrm{g} / \mu \mathrm{l}$ dissolved in $0.9 \%$ saline) was used to temporarily inactivate the mPFC. Microinjection procedures were performed as previously described (Jo et al., 2007; Jo and Lee, 2010). Briefly, a 33 gauge injection cannula extending $1 \mathrm{~mm}$ below the tip of the guide cannula was connected to a $10 \mu \mathrm{l}$ syringe (Hamilton) via polyethylene tubing (PE 20). Either MUS or $0.9 \%$ saline (SAL) of the amount of $0.3 \mu \mathrm{l} /$ side was injected bilaterally at a rate of 10 $\mu \mathrm{l} / \mathrm{h}$ using an infusion pump (KD Scientific). The injection cannula was left in place for an additional 1 min to allow diffusion of the drugs from the injection tip. Rats were then returned to their home cages, and any abnormality in movement was carefully observed for $40 \mathrm{~min}$ before they were placed on the maze.

Single-unit recording and postsurgical procedures. After a week of recovery, rats were returned to a food-restricted diet and spontaneous neural activity in the VTA was monitored as follows: the electrode interface board of the microdrives was connected to preamplifiers, and the outputs were transferred to a Cheetah data acquisition system (Neuralynx). Signals were filtered between 0.6 and $6 \mathrm{kHz}$, and digitized at $16 \mathrm{kHz}$. Neuronal spikes were recorded for $2 \mathrm{~ms}$ after the voltage deflection exceeded a predetermined threshold at 500-7000 $\times$ amplification. VTA neurons showing low firing rates and wide spike widths were preselected to increase the possibility of recording putative DA cells. If no such units were encountered, tetrodes were lowered in $40 \mu \mathrm{m}$ increments, up to $160 \mu \mathrm{m}$ per day, to target new units. Cells firing at high rates were recorded only if a low-firing cell was present on the same tetrode. A video camera mounted on the ceiling tracked infrared LED signals attached to the preamplifier and subsequent position data were fed to the acquisition system. To evaluate reward-related responses of VTA neurons, an event marker was also automatically entered into the data stream by "lickdetectors" (custom designed by Neuralynx) connected to the food cups, and these timestamped a rat's first contact with rewards.

Once clearly isolated and stable units were found, the effects of mPFC inactivation on VTA cells were investigated in a within-subjects design (Fig. $1 B$ ). In a given session, rats were first tested without drugs in the first block of five trials. Either SAL or MUS was injected into the mPFC $\sim 40$ min before the second block of five trials. The drug injected on a certain day of testing was randomly chosen. An attempt was made to record the same units in both SAL and MUS sessions. If the same units were tested with both SAL and MUS injections, they were counted separately for each drug condition. On several days, an additional recording was conducted to verify which VTA cells were inhibited by the D2 agonist quinpirole $(0.4 \mathrm{mg} / \mathrm{kg}$, s.c. $)$. While rats were located on the central platform, spontaneous firing rates for $20 \mathrm{~min}$ were compared before and after the quinpirole injection. Subsequently the tetrodes were advanced to find new units. Experimental sessions continued until tetrodes passed through the VTA based on the distance traveled from the brain surface. A total of 81 sessions were tested ( 20.5 sessions per rat on average, ranging from 9 to 36 sessions).

Histology. After the completion of all recording sessions, cannula positions and tetrode locations were verified. Rats were deeply anesthetized under $4 \%$ isoflurane. The final position of each tetrode was marked by passing a $15 \mu$ A current through a subset of the tetrode tips for $15 \mathrm{~s}$. Then, the animals were given an overdose of sodium pentobarbital and transcardially perfused with $0.9 \%$ saline and a $10 \%$ formaldehyde solution. Brains were stored in a $10 \%$ formalin-30\% sucrose solution at $4^{\circ} \mathrm{C}$ for $72 \mathrm{~h}$. The brains were frozen, and then cut in coronal sections $(40 \mu \mathrm{m})$ on a freezing microtome. The sections were then mounted on gelatin-coated slides, stained with cresyl violet, and examined under light microscopy. Only cells verified to be recorded in VTA were included in the data analysis.

Data analysis. VTA single units were isolated using an Offline Sorter (Plexon). Various waveform features, such as the relative peak, valley, width, and principle component, were compared across multiple units simultaneously recorded from four wires of a tetrode. Only units showing good recording stability across blocks were included. Further analysis of the sorted units was performed with Matlab software (Mathworks).

Putative DA and non-DA cells were classified using a cluster analysis developed to identify DA cells in the rodent VTA (Roesch et al., 2007; Jin and Costa, 2010). This classification scheme was verified pharmacologically by intravenous infusion of DA agonists known to reduce DA cell firing. Detailed information of this analysis can be found in previous reports (Roesch et al., 2007; Takahashi et al., 2009, 2011). Briefly, using the tetrode channel with the largest peak-to-valley amplitude, two basic characteristics of the average spike waveform were determined for each cell: (1) the half time of the spike duration (i.e., measured between the first valley and the next peak); and (2) the amplitude ratio of the first positive peak and negative valley in a waveform $[(n-p) /(n+p)$, with $n$ as the first negative valley and $p$ as the first positive peak]. Then, a scatter plot including all VTA cells was constructed (Fig. 2E). The center and variance of each cluster were calculated in the absence of the neuron of interest, and then that neuron was assigned to a cluster if it was within 3 SDs of the center. A cluster showing broad half duration and low amplitude ratio was putatively classified as DAergic. Neurons that fell into multiple clusters were not classified. Spontaneous firing properties of putative DA cells were calculated from data collected during the ITIs (i.e., when rats were not engaged in the task-related behavior); these included basal firing rate and the percentage of spikes that occurred in bursts. A burst was defined as successive spiking with an interspike interval of $<80$ $\mathrm{ms}$ followed by an interspike interval of $>160 \mathrm{~ms}$ (Grace and Bunney, 1984). The differences in these firing properties between blocks were computed for each neuron to determine the effect of drug injections.

To examine the reward-related responses of putative DA cells, perievent time histograms (PETHs) were constructed at $\pm 2.5 \mathrm{~s}$ around the time of all reward acquisition-triggered events. A bin size of $50 \mathrm{~ms}$ was used for all PETHs. Reward-related DA cells were identified based on the time point of phasic responses in relation to reward acquisition (Martig and Mizumori, 2011). A DA neuron was considered as postreward responsive if its peak firing rate occurred within $250 \mathrm{~ms}$ after obtaining rewards and the peak rate was $\geq 200 \%$ of the cell's average firing rate for a given block of five trials (Fig. 3A). Another DA cell was classified as prereward responsive if its highest firing rate was observed between -250 and $0 \mathrm{~ms}$ (i.e., before reward acquisition) and the peak rate was $\geq 200 \%$ of its average firing rate (Fig. $3 C$ ). Subsequently, separate PETHs were constructed for encounters with large and small amounts of reward to determine whether there were differences in firing depending on reward magnitudes. The average postreward DA activity was measured during the $250 \mathrm{~ms}$ period after collecting rewards. For prereward DA cells, firing rates were averaged during the $250 \mathrm{~ms}$ period before reward acquisition. The same analyses were performed for non-DA cells except that longer epochs were used to identify two groups of reward-related responses. Non-DA cells were considered as postreward and prereward responsive if their peak firing rates were elicited within $500 \mathrm{~ms}$ after and before reward acquisition, respectively.

Statistical analysis. Drug effects on behavioral performance and neural responses across blocks were analyzed with repeated-measures ANOVA, followed by Bonferroni's post hoc pairwise comparisons. Pearson's correlation tests were used to establish a relationship between two variables of interest. Paired $t$ tests were performed to measure within-cell differences in firing rate during a certain reward-related epoch. Independent $t$ tests were used to compare characteristics of the spike waveform between DA cells recorded in SAL and MUS sessions. Wilcoxon signedrank tests were performed to determine significant shifts from zero in distribution plots. Chi-square tests were conducted to determine proportional differences in the number of reward-responsive cells between SAL and MUS sessions. Two-tailed $p$ values of $<0.05$ were considered statistically significant. All data are expressed as mean \pm SEM.

\section{Results}

\section{Behavioral performance}

Six rats with injection cannulas aimed at the mPFC (Fig. 2A,B) were trained in a spatial working memory task in which differen- 
A

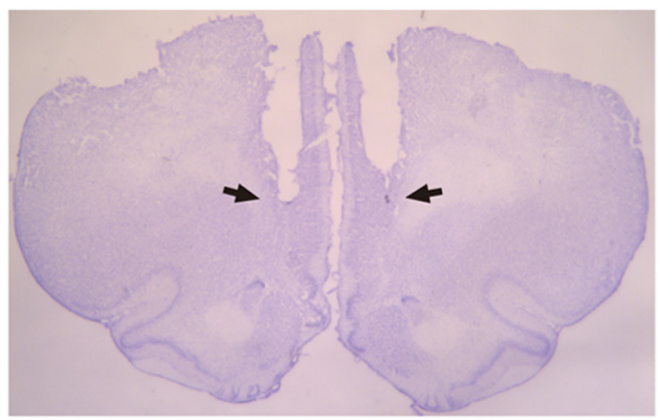

B

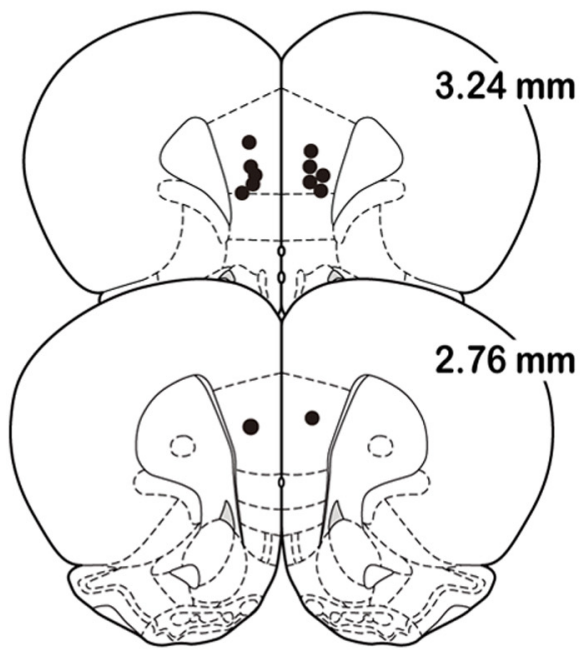

C

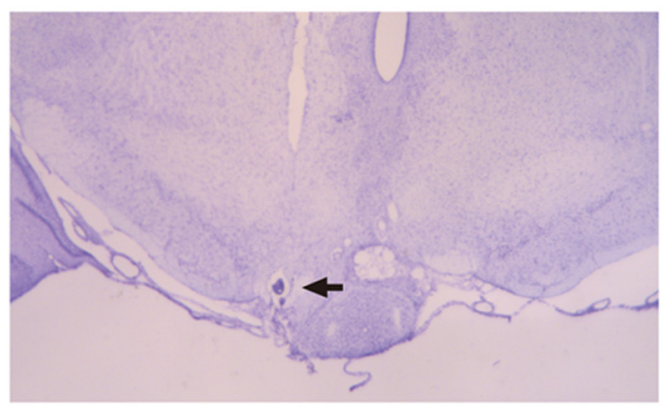

D

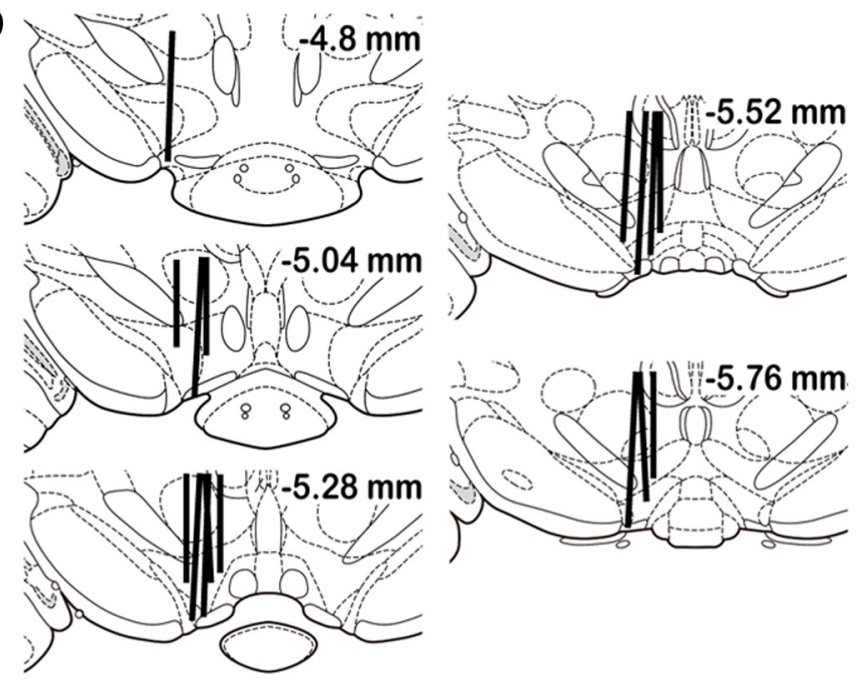

E

SAL sessions
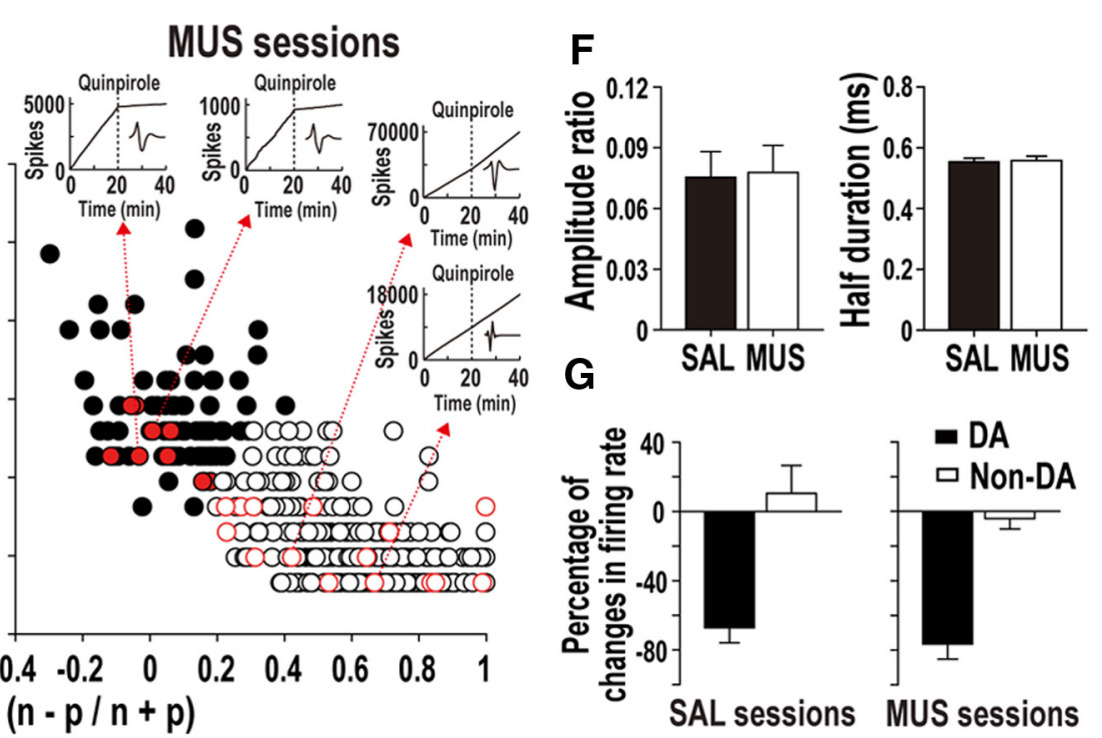

Figure 2. Histological verification of injection and recording sites and classification of putative DA cells in the VTA. $\boldsymbol{A}$, Niss--stained section showing bilateral cannula positions in the mPFC. The arrows indicate the tips of injection cannula. $\boldsymbol{B}$, Illustration of the locations of microinjection sites for all six animals. C, Representative photomicrograph of a tetrode track that ended in the VTA. The arrow shows an electrolytic lesion made after the final recording session. $\boldsymbol{D}$, Reconstruction of the tetrode tracks in the VTA. $\boldsymbol{E}$, Results of cluster analysis in SAL and MUS sessions. Putative DA cells were identified based on half spike duration and the amplitude ratio of the initial negative valley ( $n$ ) and positive peak ( $p$ ). Neurons in red were further tested with the D2 agonist quinpirole after daily recording sessions. Inset cumulative sum plots show the effects of quinpirole on spontaneous firing in DA and non-DA cells. $F$, Average amplitude ratio and half duration of DA cells in SAL and MUS sessions. $\mathbf{G}$, Percentage of changes in firing rate induced by quinpirole.

tial amounts of reward were available on alternating arms of a radial eight-arm maze (Fig. $1 A$ ). To examine the effects of mPFC inactivation on behavioral performance, the first block of five trials was tested without drugs and the second block occurred after either SAL injections (50 sessions) or MUS injections (41 sessions) into the mPFC (Fig. $1 B$ ). The animals made a small number of errors before drug infusion (block 1), and the same performance level was observed after SAL was injected before the second block (Fig. 1C). However, MUS injections caused a marked increase in errors compared with the first block. An ANOVA with repeated measures showed significant effects of $\operatorname{drug}\left(F_{(1,5)}=27.09, p=0.003\right)$ and block $\left(F_{(1,5)}=29.63, p=\right.$ 

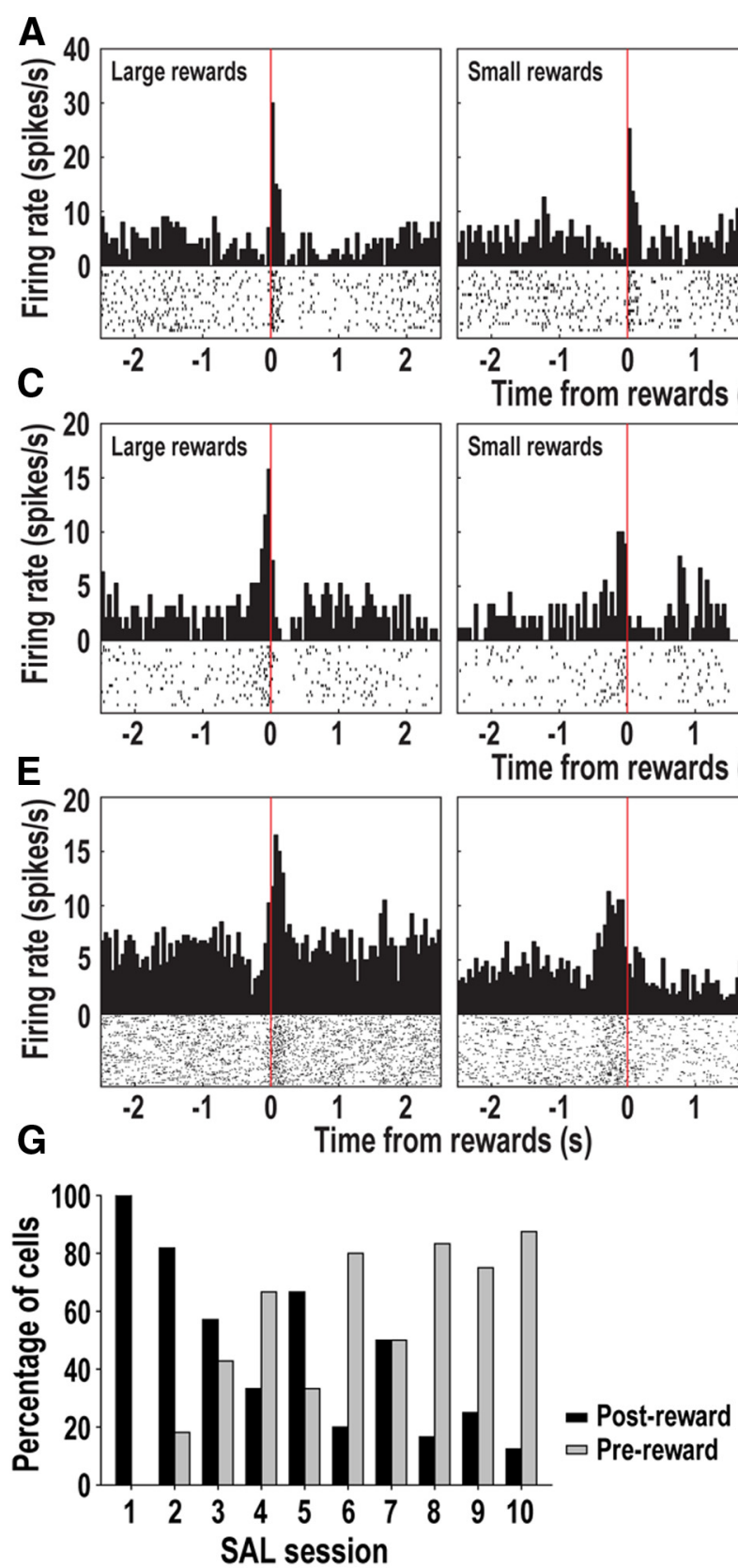

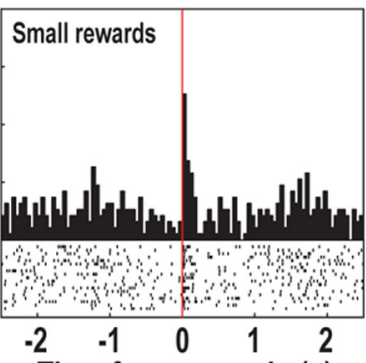

Time from rewards (s)
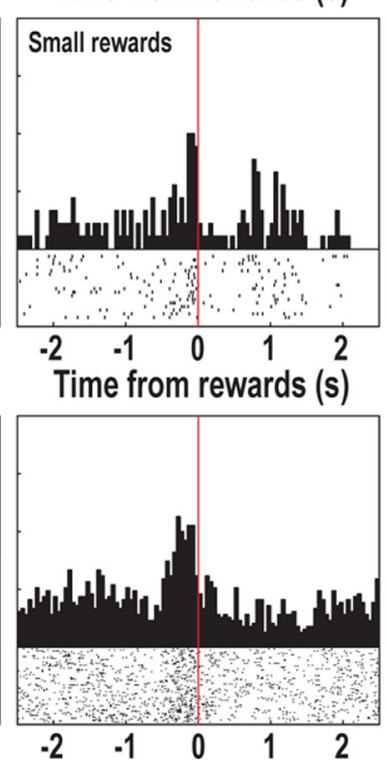

\section{$\mathrm{H}$}
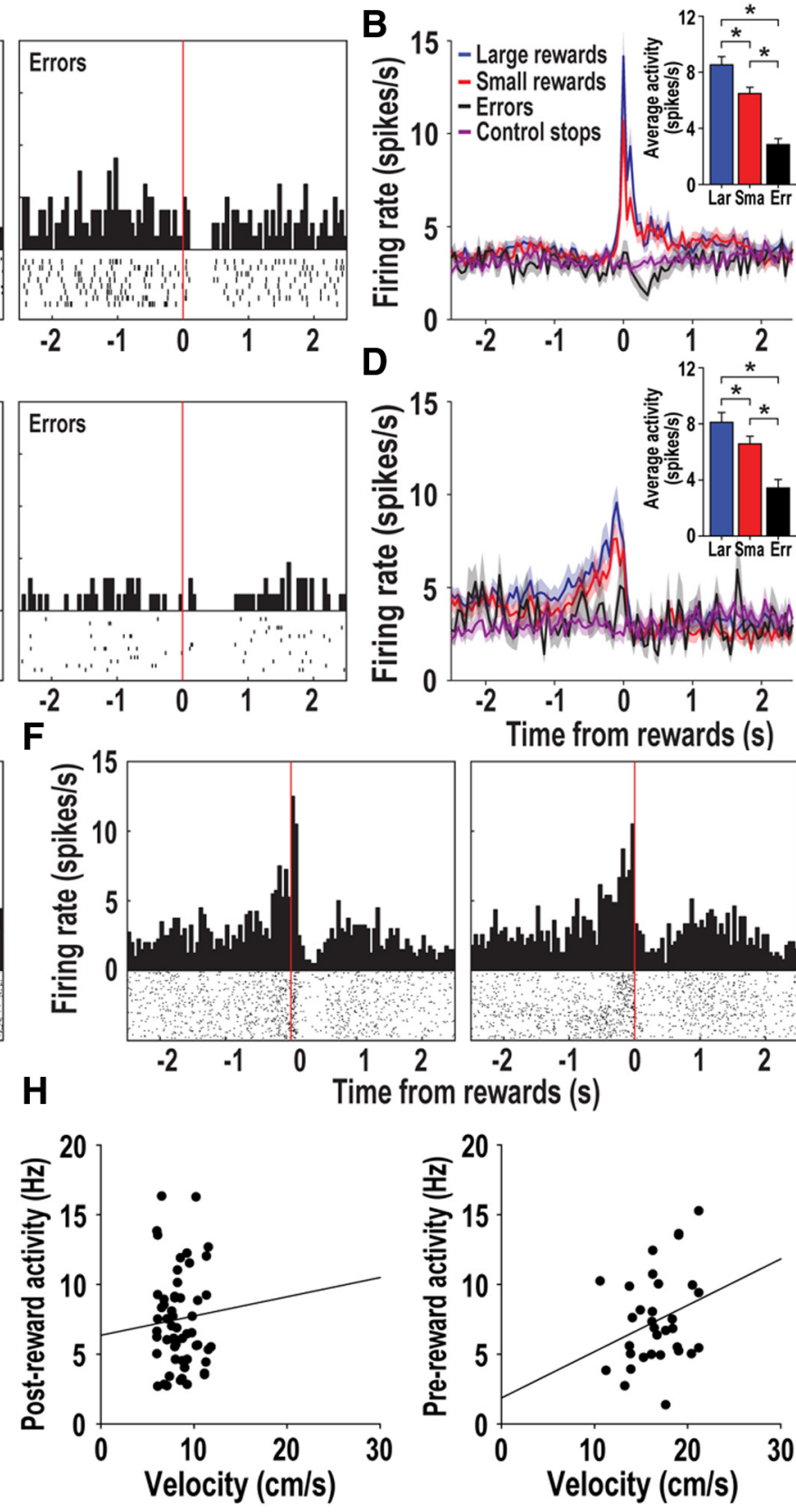

Figure 3. Phasic DA responses during the spatial working memory task. $A$, Representative DA cell showing postreward responses upon the acquisition of different amounts of reward in the first block of a SAL session (red vertical lines; bin width, 50 ms). B, Population PETHs of postreward DA cells. The shaded regions indicate SEM. Inset bar graphs show average postreward activity measured during the 250 ms epoch after reward acquisition. Postreward responses at the ends of the arms were compared with the firing patterns when rats stopped on the central platform (control stops). C, Single-unit example of prereward DA activity in the first block of a SAL session. D, Population responses of all prereward DA cells. Average responses in inset were measured during the 250 ms window before reward acquisition. $\boldsymbol{E}, \boldsymbol{F}$, Two DA cells showing a response shift from after to before reward acquisition for two consecutive recording days. Postreward activity in $\boldsymbol{E}$ and prereward activity in $\boldsymbol{F}$ were recorded in MUS sessions. Note that the prereward activity in $\boldsymbol{F}$ was increased in the second block after mPFC inactivation (bottom half of the raster plot), compared with the drug-free first block (top half). G, Distributions of postreward and prereward DA cells across the first 10 SAL sessions. More postreward cells were observed earlier in training while more prereward cells were recorded later in training. $\boldsymbol{H}$, Correlations between DA activity and average velocity during postreward and prereward periods. No significant relationship was found between the two factors in either period. * $p<0.001$.

$0.003)$, as well as a significant interaction effect between the two variables $\left(F_{(1,5)}=36.04, p=0.002\right)$. Post hoc pairwise comparisons (Bonferroni's $t$ test) revealed a significant difference in errors across blocks in MUS sessions $(p=0.002)$, but not in SAL sessions $(p=0.65)$. Subsequent analysis of the type of errors also found significant effects of $\operatorname{drug}\left(F_{(1,5)}=38.17, p=0.002\right.$; Fig. $1 D)$, error type $\left(F_{(1,6)}=15.73, p=0.011\right)$, and an interaction $\left(F_{(1,5)}=12.39, p=0.017\right)$. Bonferroni's post hoc comparisons demonstrated that rats made both across-phase and within- phase errors significantly more often in the MUS-injected block than in the SAL-injected block $(p<0.004)$.

Animals' foraging behavior was further examined to determine possible causes for the deficits in working memory performance after $\mathrm{mPFC}$ inactivation. First, mPFC inactivation seemed to increase perseverative behavior. For instance, MUS-injected rats tended to visit back and forth between two error arms. To quantify this perseverative behavior, repetitive visits to the same arms with no more than one intervening choice (i.e., visiting 
order in an A-B-A fashion) were measured (Fig. 1E). An ANOVA with a repeated-measures design showed significant effects of drug $\left(F_{(1,5)}=12.42, p=0.017\right)$, block $\left(F_{(1,5)}=10.74, p=\right.$ $0.022)$, and the interaction between the variables $\left(F_{(1,5)}=11.59\right.$, $p=0.019)$. Post hoc pairwise comparisons (Bonferroni's $t$ test) demonstrated that repetitive visits were significantly increased after MUS injections into the $\mathrm{mPFC}(p=0.02)$, but not after SAL injections $(p=0.11)$. Second, MUS injections into the mPFC seemed to disrupt an ability to inhibit inappropriate behavior at a critical time for proper decision making. Specifically, normal and SAL-injected rats typically paused on the central platform before choosing the next maze arm between two consecutive arm entries. By contrast, MUS-injected rats often made immediate choices without any pauses (Fig. $1 F$; $\sim 2.5 \mathrm{~s}$ when rats reached the central platform), which increased animals' velocity as they traversed the central platform. Together, these results suggest that the $\mathrm{mPFC}$ plays a critical role in selecting/inhibiting responses and its dysfunction leads to spatial working memory deficits (Seamans et al., 1995; Floresco et al., 1997; Taylor et al., 2003).

Previous studies have shown that foraging rats in the current task can discriminate between the locations of large and small rewards by showing a preference for arms associated with large rewards when both large-reward and small-reward arms are simultaneously available during the test phase (Pratt and Mizumori, 2001; Puryear et al., 2010; Norton et al., 2011). Thus, we next determined whether $\mathrm{MPFC}$ inactivation affected the animals' preference for large over small rewards. In drug-free conditions, rats first visited large-reward arms during the test phase, then progressed to small-reward arms (Fig. $1 G$ ), as indicated by negative correlations between the first four choices of the test phase and the probability of choosing large rewards (block 1 of SAL sessions; $r=-0.84, p<0.001$, block 1 of MUS sessions; $r=-0.8$, $p<0.001)$. This bias was maintained after SAL injections $(r=$ $-0.79, p<0.001)$, but not MUS injections $(r=-0.34, p=0.11)$. These results indicated that the $\mathrm{MPFC}$-inactivated rats failed to use an optimal foraging strategy based on expected reward values.

\section{Prediction error signals by DA cells in foraging rats}

Single units in the VTA were recorded while rats performed the differential reward, spatial memory task. Histological verification confirmed that all cells reported here were recorded in the VTA (Fig. 2C,D). A cluster analysis was performed to identify DA neurons using two characteristics of the waveform: half spike duration and amplitude ratio (Roesch et al., 2007; Takahashi et al., 2009, 2011; Jin and Costa, 2010) (Fig. 2E). The analysis classified 105 of 465 neurons recorded in SAL sessions as DAergic and 98 of 440 as DAergic in MUS sessions. The half durations and amplitude ratios were similar to those reported in previous studies (Roesch et al., 2007; Takahashi et al., 2011). Independent $t$ tests showed no significant differences in the waveform characteristics of DA cells between SAL and MUS sessions (amplitude ratio, $t_{(201)}=0.13, p=0.89$; half duration, $t_{(201)}=0.23, p=0.82$; Figure $2 F$ ). To confirm the validity of the electrophysiological criteria, 42 cells in SAL sessions and 24 neurons in MUS sessions were further tested with the DA agonist quinpirole after daily recording sessions. VTA cells whose firing was inhibited after quinpirole injections fell into the DA cluster in the waveform analysis (Fig. $2 E$ ). On average, quinpirole reduced the firing rate of DA cells by $67.2 \%$ of baseline in SAL sessions and $76.5 \%$ in MUS sessions (Fig. 2G).

We investigated which events triggered phasic activation of DA cells in the foraging animals. A large number of DA cells (59 of 105 cells in SAL sessions and 42 of 98 neurons in MUS sessions; no difference in the proportion of the DA cells between the two sessions: $\chi^{2}$ test, $\left.\chi^{2}(1)=3.61, p=0.06\right)$ exhibited brief excitation after rats encountered rewards at the end of maze arms. The postreward activation of DA cells identified in SAL sessions was characterized in terms of whether different amounts of rewards elicited different reward responses. As depicted by PETHs in Figure $3 A, B$, an individual cell and the corresponding population activity showed stronger postreward responses to large rewards than to small ones. The same DA cells were inhibited by the absence of reward when animals made error choices by reentering previously visited arms. To quantify the magnitude of neural responses to the three reward conditions, the average firing rate during the $250 \mathrm{~ms}$ period after obtaining rewards was measured (Fig. 3B, inset). An ANOVA with repeated measures showed a significant difference across reward sizes $\left(F_{(2,116)}=\right.$ $154.78, p<0.001)$, indicating a larger amount of reward elicited greater neural activation.

DA cells also displayed another type of reward response, one that preceded reward encounters [32 of 105 cells in SAL sessions and 41 of 98 neurons in MUS sessions; no difference in the proportion of the DA cells between the two sessions: $\chi^{2}$ test, $\chi^{2}(1)=$ $2.84, p=0.09]$. A representative cell in Figure $3 C$ was phasically excited before animals first licked the food cups and this activation disappeared during reward consumption. The prereward response was not evident when rats found no reward in error choices. Similar to postreward responses, the population activity showed that the magnitude of the prereward activation was scaled to the size of expected rewards (Fig. 3D). A repeatedmeasures ANOVA confirmed a significant difference in the average firing rate during the $250 \mathrm{~ms}$ before the acquisition of rewards $\left(F_{(2,62)}=48.38, p<0.001\right)$. Post hoc comparisons with Bonferroni correction demonstrated that the average response to large rewards was higher than that to small rewards $(p<0.001)$. The prereward activation in error choices was significantly smaller than those of two differential reward conditions $(p<0.001)$.

Next, it was determined whether the two types of phasic DA responses resulted from a shift in prediction error signaling of a primary reward to its predictive cues (Schultz et al., 1997; Pan et al., 2005; Day et al., 2007; Clark et al., 2010; Cohen et al., 2012). Since an attempt was made to record the same cells across two consecutive drug-testing days, it was possible to examine a response shift across the $2 \mathrm{~d}$. Although some DA cells (Fig. 3E,F) exhibited a response shift from after to before the acquisition of rewards, most DA cells maintained their response patterns across the $2 \mathrm{~d}$. Thus, response shifts were further analyzed at the population level. The percentages of DA cells showing the two different reward responses over the first $10 \mathrm{SAL}$ sessions are depicted in Figure $3 G$. A Pearson's correlation test revealed that the proportion of postreward DA cells became smaller as recording sessions progressed $(r=-0.85, p=0.002)$. Instead, more prereward DA cells were observed in the latter recording sessions. This response shift is consistent with evidence from previous studies showing that phasic responses to expected rewards gradually disappear over training in rodents (Pan et al., 2005; Cohen et al., 2012). The close temporal proximity between the prereward activation and reward acquisition suggests that DA cells in foraging animals rely on sensory information emanating from a reward itself (e.g., visual identification of the physical presence of chocolate milk and/or olfactory detection of its odor) to signal prediction errors.

The literature suggests that animals' movement influences the activity of DA cells in the VTA (Puryear et al., 2010; Wang and Tsien, 2011). It is possible that motoric variables, such as the cessation of forward movement, generated the phasic responses 
observed around reward encounters in the current study. However, this idea is unlikely because neither postreward nor prereward responses were elicited during error choices even though rats showed the same approach-stop movement between rewarded and nonrewarded visits (Fig. $3 B, D$ ). Additionally, similar approach-stop behavior that occurred on the central platform was analyzed for comparison (i.e., when rats stopped for at least $1 \mathrm{~s}$ after inbound journeys to the maze center). No excited responses were observed around these "control stops." Finally, no significant relationships were found between the average neural activity and moving velocity measured during the same postreward and prereward time window (Pearson's correlation test: postreward, $r=0.06, p=0.64$; prereward, $r=0.28, p=0.12$; Fig. $3 H$ ). Together, these results indicated that the two DA responses represent perceived and expected reward values rather than movement-related signals.

\section{Effects of mPFC inactivation on DA cells in the VTA}

To examine the functional contribution of the mPFC to computations of DAergic prediction error signals, the mPFC was temporarily inactivated before the second block of trials was tested. Comparisons of spontaneous firing patterns before and after drug injections were first conducted by calculating difference scores across blocks for all DA neurons (Fig. $4 A, B$ ). In SAL sessions, Wilcoxon signed-rank tests showed that these scores in spontaneous firing rate and percentage of spikes in bursts were distributed around zero $(p>0.34)$. However, the distributions of the two measures in MUS sessions were significantly shifted in the negative direction (spontaneous firing rate, $p<0.001$; percentage of spikes in bursts, $p<0.001$ ), implying that the excitability of DA cells was reduced after mPFC inactivation.

Next, the two types of phasic responses around the acquisition of rewards were compared across blocks. Most postreward DA cells displayed similar levels of phasic activation upon the acquisition of all rewards regardless of whether the $\mathrm{MPFC}$ was inactivated or not (Fig. 4C). The difference scores of individual neuronal responses across blocks were distributed around zero in both SAL sessions (Wilcoxon signed-rank tests, $p=0.61$ ) and MUS sessions ( $p=0.21$; Fig. $4 D)$. Even when the postreward responses were separated according to different reward magnitudes at the end of maze arms (Fig. $4 E$ ), population PETHs showed no significant alternations in firing in either SAL or MUS sessions. During error choices, the brief inhibition of postreward cells in response to the absence of reward was also not affected by $\mathrm{mPFC}$ inactivation. The difference scores comparing their inhibited responses between blocks were not significantly shifted in either direction in SAL sessions $(p=0.79)$ or in MUS sessions $(p=0.78)$.

For the prereward activity, individual DA cells were not affected by SAL injections into the MPFC (Fig. $4 F$ ). However, MUS injections dramatically increased the magnitude of the prereward activation for forthcoming rewards, relative to baseline in the first block. A Wilcoxon signed-rank test confirmed that the overall distribution of difference scores comparing prereward responses across blocks was significantly shifted above zero in MUS sessions $(p=0.02)$, but not in SAL sessions $(p=0.08)$, indicating that the prereward activation was elevated after MUS injections. Similar results were observed when the prereward responses were subdivided by reward size (Fig. $4 H$ ). Population PETHs showed that DA cells exhibited earlier and stronger prereward responses before obtaining both large and small rewards when the mPFC was temporarily inactivated. The MUS-induced increment in prereward responses may not be attributed to other aspects of food approach behavior, since animals' locomotor velocities within the $1 \mathrm{~s}$ period before reward acquisition were comparable between blocks in MUS sessions (Fig. $1 F$ ). When the rats failed to detect reward-predicting sensory information during error choices, prereward DA cells exhibited normal basal firing rates (Fig. $4 H$ ) and their difference scores across blocks were not different from zero in either SAL $(p=0.44)$ or MUS sessions $(p=0.72)$. Overall, these results suggest that mPFC dysfunction selectively influences DA cells' response to rewardpredicting cues, but not to actual rewards.

\section{Reward-related responses by Non-DA cells}

To investigate how non-DA cells in the VTA responded in the foraging rats, we analyzed 360 cells in SAL sessions and 342 neurons in MUS sessions that fell outside the electrophysiological criteria for DA cells (Fig. 2E). Spontaneous firing rates of all non-DA cells ranged from 0.2 to $94 \mathrm{~Hz}$. These neurons were further subdivided into two reward-related groups similar to the way that DA cells were classified. Postreward non-DA cells [70 of 360 in SAL sessions and 53 of 342 in MUS sessions; no difference in the proportion of the non-DA cells between the two sessions: $\chi^{2}$ test, $\chi^{2}(1)=1.89, p=0.17$ ] displayed a sudden increase in firing after reward acquisition, followed by a slow decay of the excitation during reward consumption (Fig. 5A). Population PETHs of non-DA cells recorded in SAL sessions showed that postreward responses were graded according to reward size (Fig. $5 B$ ). An ANOVA with a repeated-measures design found a significant difference in the average postreward activation measured during the $500 \mathrm{~ms}$ after obtaining rewards $\left(F_{(2,138)}=21.39, p<\right.$ 0.001). Post hoc comparisons with Bonferroni correction revealed that large rewards elicited greater responses than small rewards $(p<0.001)$. The postreward response in error choices was significantly smaller than those of two rewarded conditions $(p<0.001)$.

A separate group of non-DA cells [75 of 360 in SAL sessions and 91 of 342 in MUS sessions; no difference in the proportion of the non-DA cells between the two sessions: $\chi^{2}$ test, $\chi^{2}(1)=3.24$, $p=0.07$ ] exhibited strong prereward responses around the places when the animals traveled halfway down the length of maze arms (i.e., 600-500 ms before reward acquisition; Fig. 5C), which was earlier than prereward activity by DA cells. The same cells were excited similarly even when rewards were not available during error choices. An ANOVA with repeated measures confirmed these observations $\left(F_{(2,148)}=3.21, p=0.04\right)$ : the average prereward response to large rewards was greater than those to the other reward conditions $(p<0.001)$, while the activation in error choices was not different from that preceding small rewards $(p=0.14)$.

We further determined whether the two types of rewardrelated responses were represented by the same non-DA cells or independently by different groups of non-DA cells. There were no non-DA cells showing a response shift from postreward to prereward within two consecutive recording sessions. Additionally, the two reward responses were evenly distributed over the first 10 SAL sessions without significant changes in either increasing or decreasing direction (Pearson's correlation test, $r=0.58$, $p=0.08$; Fig. $5 E$ ). Thus, it appears that the two reward activities are encoded by different sets of non-DA cells.

The long-lasting postreward activation during only rewarded conditions suggests that postreward non-DA cells reflect reward consumption. By contrast, the prereward responses by non-DA cells were present in the absence of reward in error choices, which raises a possibility that the prereward activation results from be- 

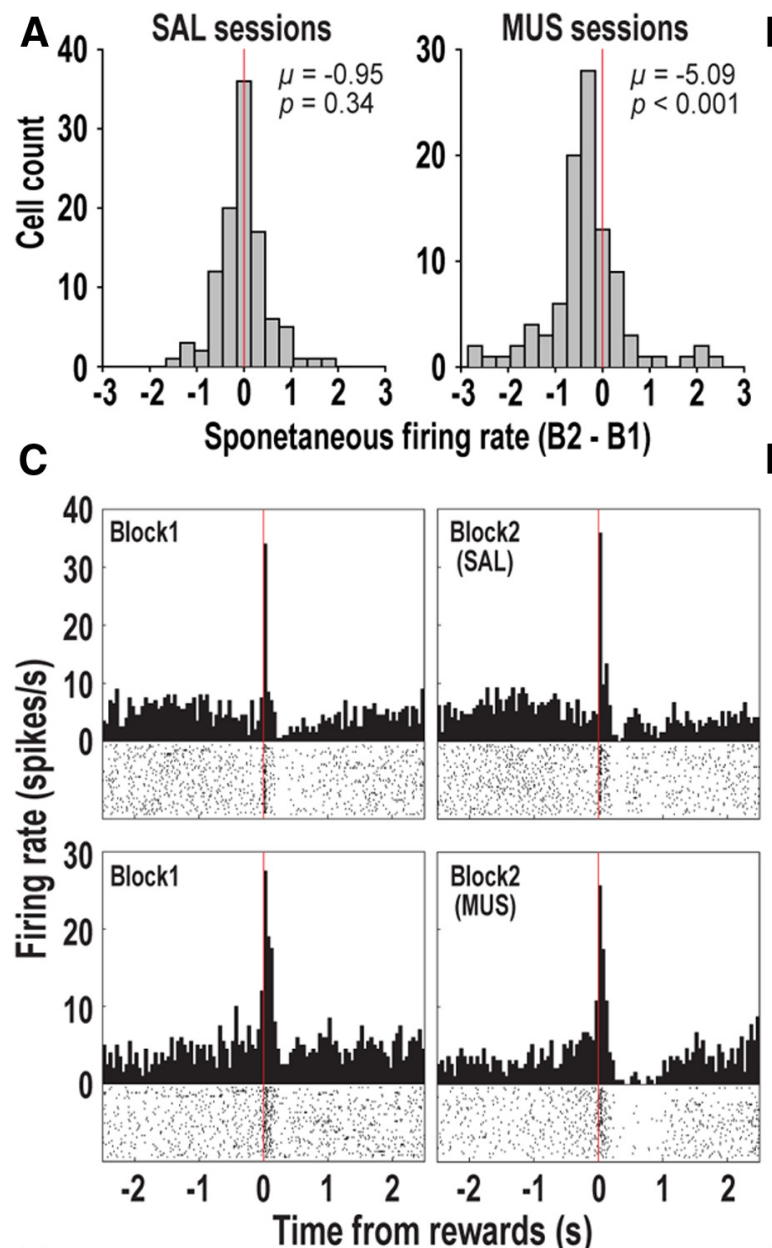

F

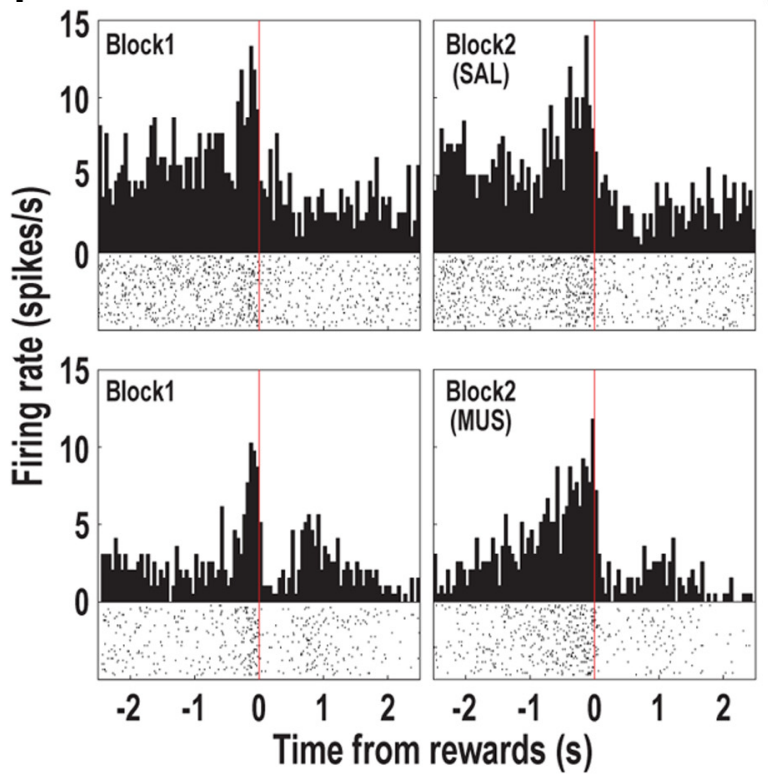

B
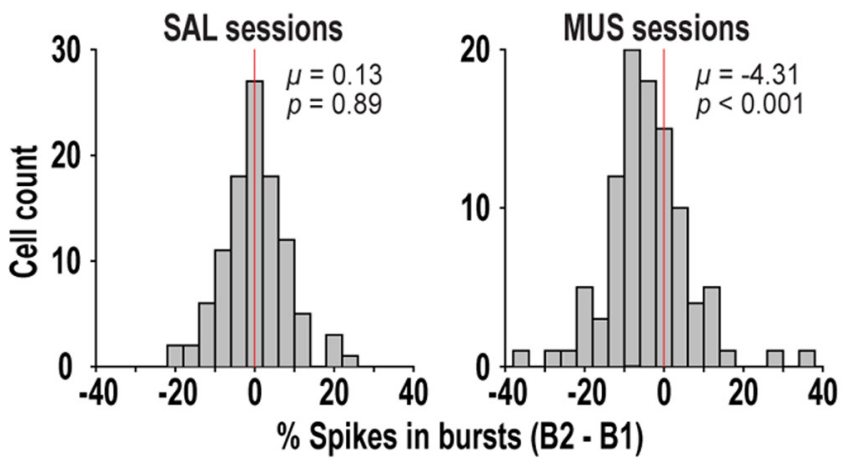

D

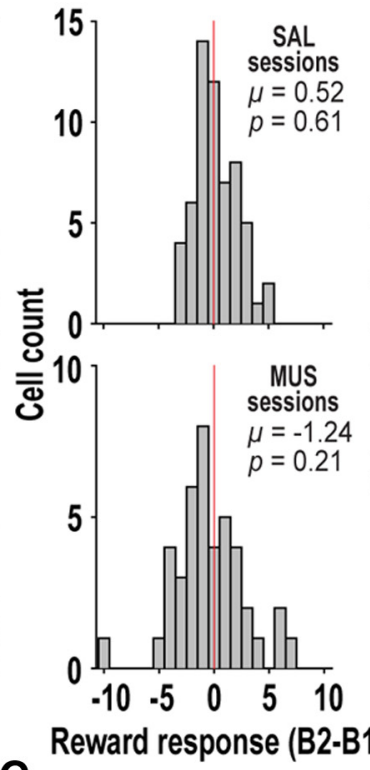

G

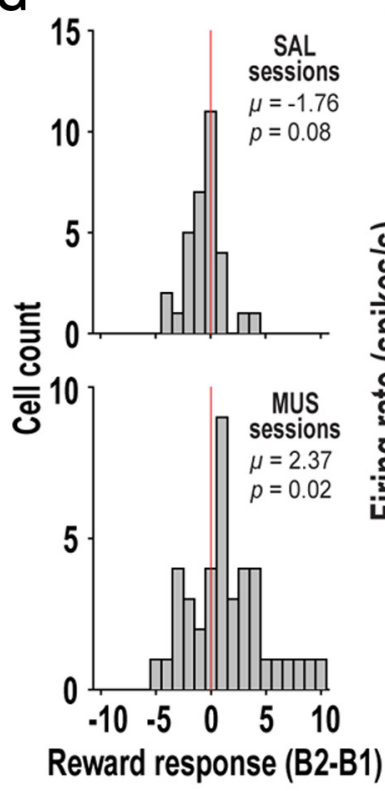

E

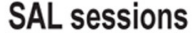

MUS sessions

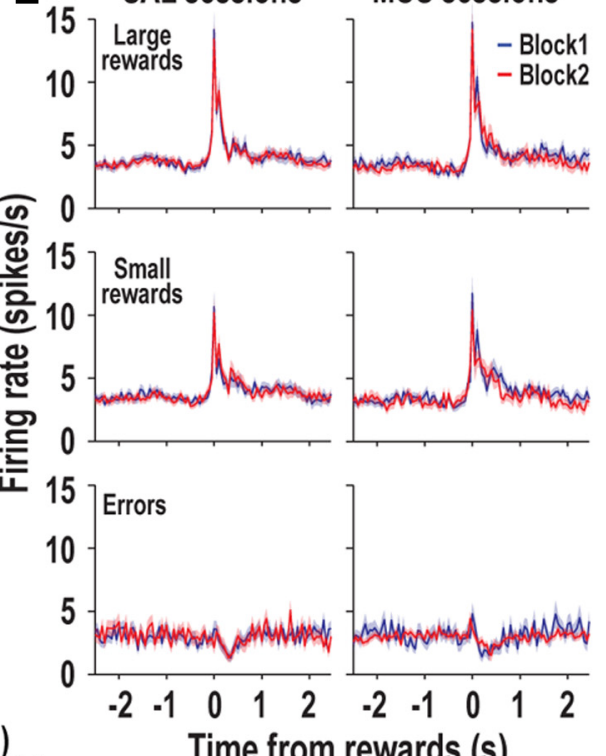

Time from rewards (s)

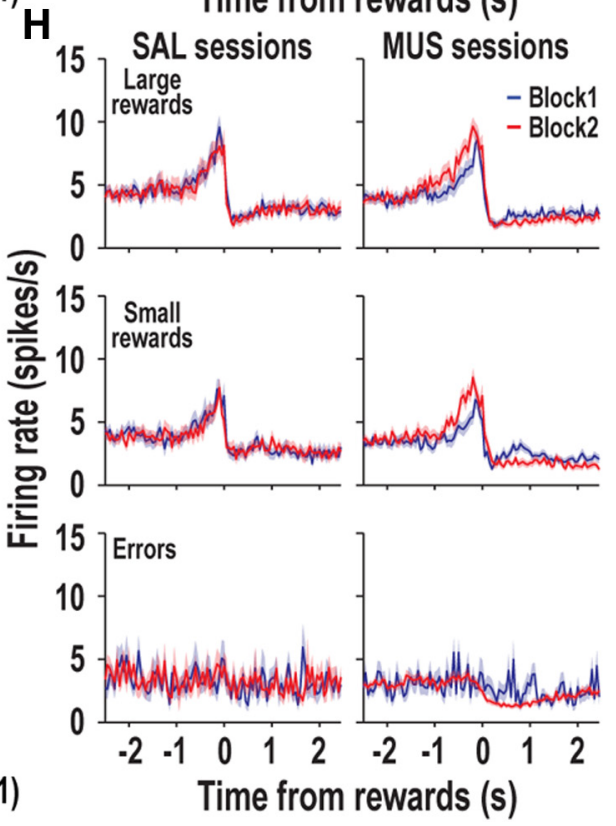

Figure 4. Effects of mPFC inactivation on DA cells. $\boldsymbol{A}, \boldsymbol{B}$, Distributions of difference scores comparing spontaneous firing rates $(\boldsymbol{A})$ and percentages of spikes in bursts ( $\boldsymbol{B}$ ) between blocks. Also shown are the result of Wilcoxon signed-rank test ( $p$ ) and the average difference score ( $\mu$ ). C, PETHs of two postreward DA cells (reward acquisition at red vertical lines; bin width, $50 \mathrm{~ms}$ ). After basal reward responses were recorded in the first block, the effects of either SAL or MUS injection into the mPFC on the same cells were examined in the second block. D, Distributions of changes in the average postreward activity across blocks in SAL and MUS sessions. $\boldsymbol{E}$, Population PETHs of all postreward DA cells in SAL and MUS sessions. The shaded regions indicate SEM. $\boldsymbol{F}$, Two representative prereward DA cells recorded in SAL and MUS sessions. Bilateral MUS, but not SAL, injections into the mPFC noticeably increased the prereward activity. G, Distributions of difference scores comparing average prereward activity across blocks. $\boldsymbol{H}$, Population PETHs of all prereward DA cells in SAL and MUS sessions. 
A
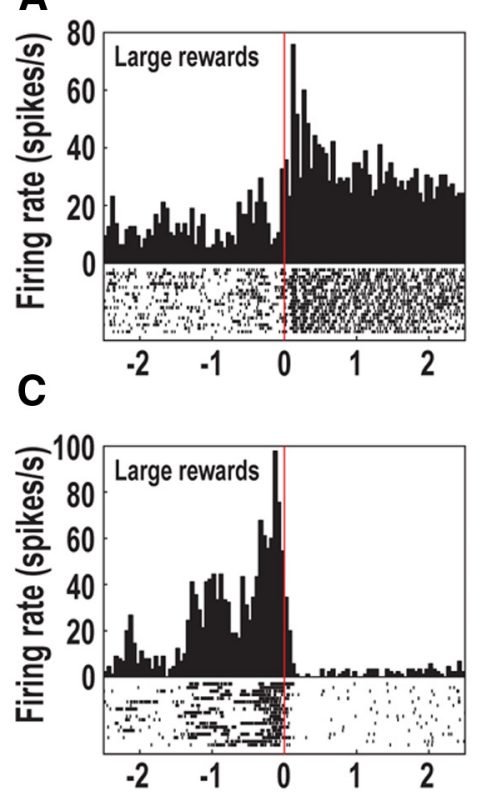

E

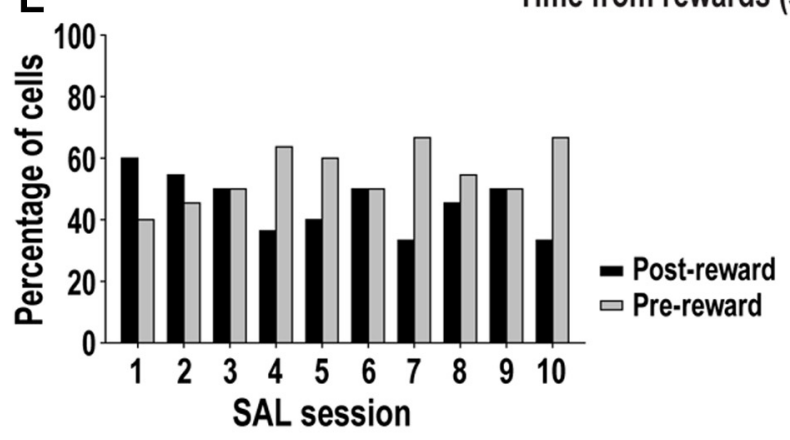

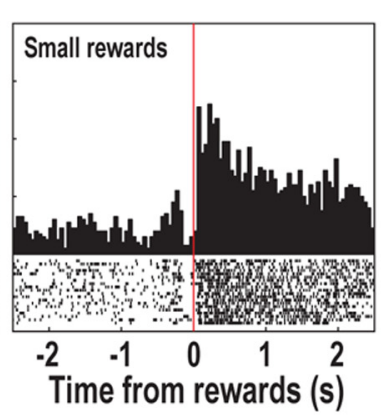
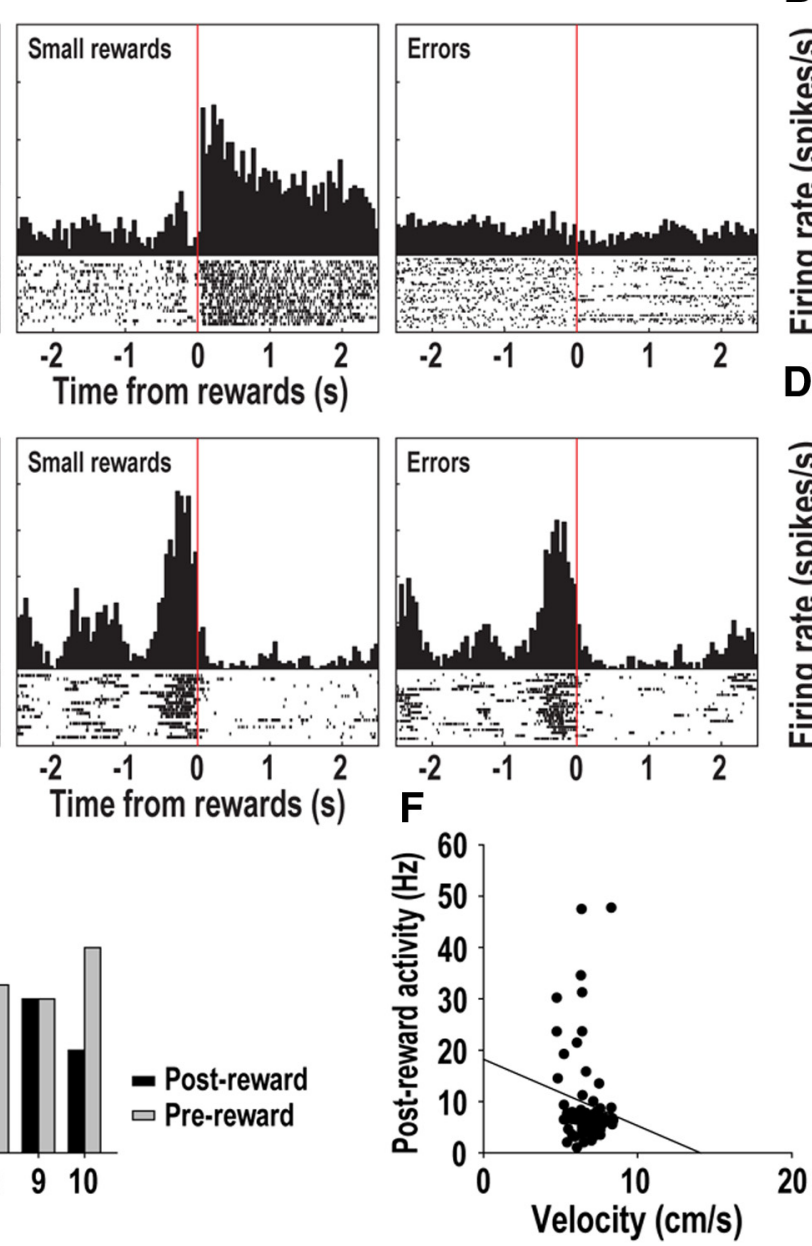

B
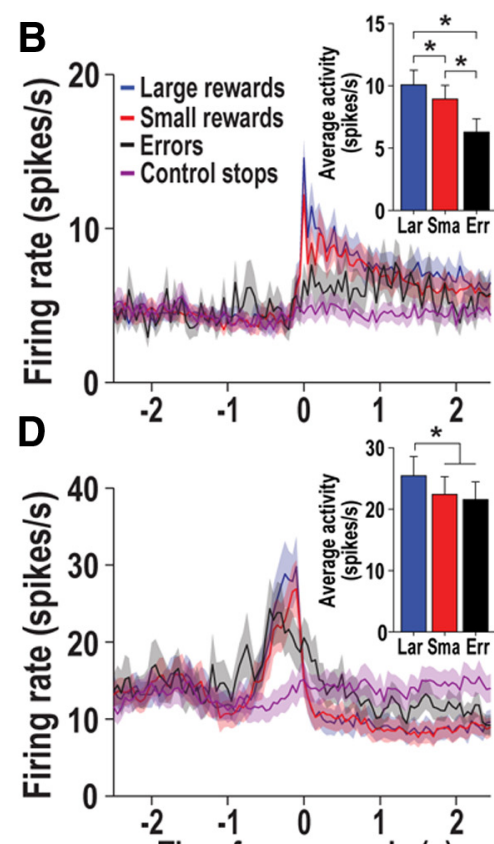

Time from rewards (s)

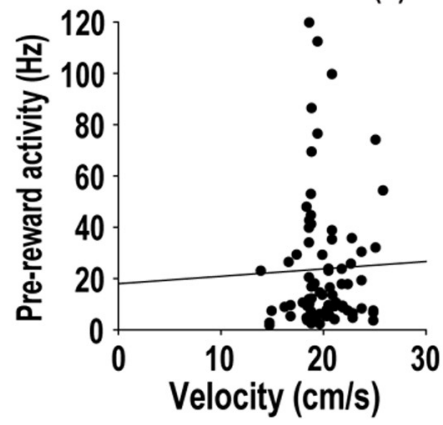

Figure 5. Non-DA cells showing reward-related responses. $A$, Postreward activity by an individual non-DA cell upon the acquisition of different amounts of reward in the first block of a SAL session (red vertical lines; bin width, 50 ms). $\boldsymbol{B}$, Population PETHs of all postreward non-DA cells. The shaded regions indicate SEM. Inset bar graphs show average postreward responses measured during the $500 \mathrm{~ms}$ window after reward acquisition. Postreward activity was compared with the firing patterns when rats showed similar approach-stop behavior on the central platform (control stops). C, Representative prereward non-DA activity in the first block of a SAL session. D, Population activity of all prereward non-DA cells. Average responses in inset were measured during the 500 ms window before reward acquisition. $\boldsymbol{E}$, Distributions of postreward and prereward non-DA cells across the first 10 SAL sessions. $\boldsymbol{F}$, Correlations between non-DA activity and average velocity during postreward and prereward periods. ${ }^{*} p<0.001$.

havioral changes before arriving at food cups. However, prereward non-DA cells were not excited when rats showed the similar approach-stop movement on the central platform (Fig. 5D, control stops). Moreover, the prereward responses were not correlated with approaching velocities measured in the $500 \mathrm{~ms}$ window before reward acquisition (Pearson's correlation test; $r=0.03, p=0.81$; Fig. $5 F)$. Thus, the prereward activation is not directly related to animals' movement. Instead, as suggested by a previous report (Cohen et al., 2012), it seems likely that the prereward non-DA cells represent the expectation of upcoming rewards while rats approached them. This idea can account for the prereward activation in error choices, because it is reasonable to assume that rats revisited a previously visited arm in expectation of rewards.

Effects of mPFC inactivation on non-DA cells in the VTA It has been shown that mPFC neurons synapse with GABA cells as well as DA neurons in the VTA (Sesack and Pickel, 1992; Carr and Sesack, 2000). To determine whether temporary mPFC inactivation affected the activity of non-DA cells, basal activity levels were first compared before and after each drug treatment. The differ- ence scores of spontaneous firing rates were distributed around zero in SAL sessions (Wilcoxon signed-rank test, $p=0.09$; Fig. $6 A$ ). There were a number of non-DA cells whose spontaneous firing was not altered after MUS injections. However, the overall distribution in MUS sessions was shifted in the negative direction $(p<0.001)$, indicating that the spontaneous firing rates of non-DA cells were decreased after mPFC inactivation.

Next, the two reward responses were analyzed. Individual postreward non-DA cells exhibited similar responses across blocks regardless of the drug injected into the mPFC (Fig. 6B). Difference scores comparing each neuron's responses between blocks were distributed around zero in both SAL (Wilcoxon signed-rank test, $p=0.09$ ) and MUS sessions ( $p=0.39$ ). Population PETHs in Figure $6 D$ also confirmed that MUS injections into the $\mathrm{mPFC}$ caused no evident alternations in postreward response. During error choices, these non-DA cells also showed no significant shift in the distribution of difference scores from zero in either SAL $(p=0.25)$ or MUS sessions $(p=0.31)$. On the contrary, $\mathrm{mPFC}$ inactivation induced a profound decrease in prereward response (Fig. $6 E$ ). The distribution of difference scores was significantly shifted below zero in MUS sessions $(p<0.001$; 

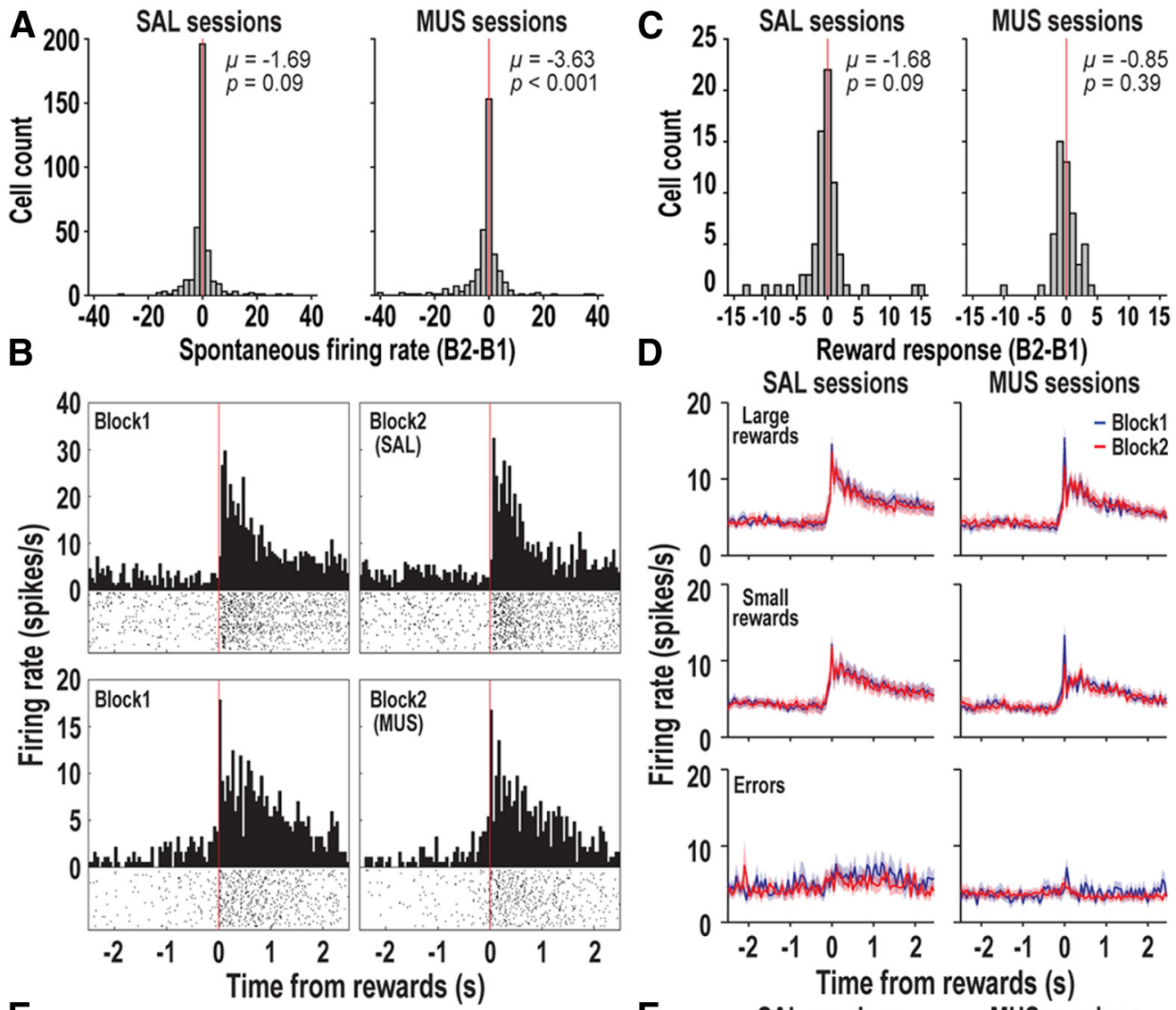

$\mathbf{E}$
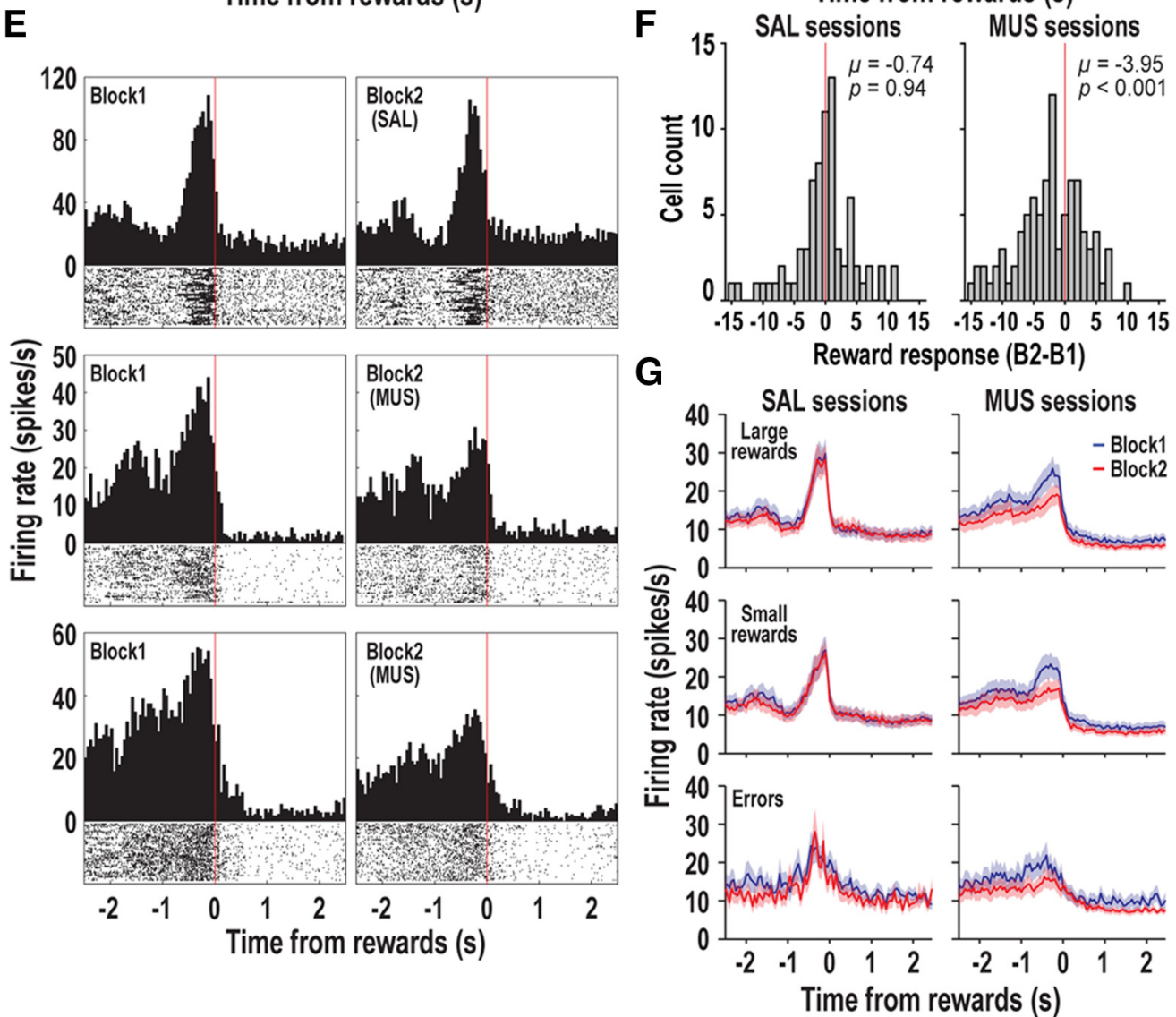

Figure 6. Effects of $\mathrm{mPFC}$ inactivation on non-DA cells. $A$, Distributions of difference scores comparing spontaneous firing rates across blocks. The numbers in each graph indicate the result of Wilcoxon signed-rank test $(p)$ and the average difference score $(\mu) . B$, PETHs of two postreward non-DA cells with either SAL or MUS injections (reward acquisition at red vertical lines; bin width, $50 \mathrm{~ms}$ ). C, Difference scores in postreward responses between blocks in SAL and MUS sessions. D, Population responses of all postreward DA cells in three different reward (Figure legend continues.) 
Fig. $6 F)$, whereas no such a shift was found in SAL sessions $(p=$ $0.94)$. When the prereward responses to all rewards were broken down by reward size, non-DA cells exhibited significantly reduced responses to both large and small rewards during the 500 ms epoch before reward acquisition (paired $t$ test, $t_{(90)}>3.75$, $p<0.001$; Fig. 6G). The prereward activity in error choices was also decreased after mPFC inactivation. Difference scores of prereward responses across blocks were distributed below zero in MUS sessions $(p=0.03)$ and the corresponding population responses after MUS injections were significantly lower than those before the drug treatment $\left(t_{(90)}=2.75, p=0.007\right.$; Fig. $\left.6 G\right)$. However, SAL injections into the $\mathrm{mPFC}$ resulted in no significant changes in the distribution of difference scores $(p=0.51)$ and in the population activity $\left(t_{(74)}=0.54, p=0.59\right)$. Therefore, these results suggest that the $\mathrm{mPFC}$ is involved in modulating non-DA cells that signal reward expectancy, but not reward consumption.

\section{Discussion}

The present study investigated whether the loss of mPFC function impacted prediction error signaling by DA cells as well as two reward-related representations by non-DA cells in foraging rats. Reversible inactivation of the $\mathrm{mPFC}$ induced a significant increase in DAergic prediction error signals in response to reward-predicting stimuli, but not to actual rewards. The same manipulation of the MPFC also caused a selective decrease in the representation of expected rewards by non-DA cells but no changes in non-DA activity elicited by reward consumption. The findings that $\mathrm{MPFC}$ inactivation altered both prereward DA and non-DA responses indicate that the $\mathrm{MPFC}$ contributes to regulating VTA neural activity by providing information about expected rewards.

Numerous experimental studies and theoretical models have used Pavlovian conditioning paradigms to understand the functional roles of DAergic error signals in reinforcement learning (Montague et al., 1996; Schultz et al., 1997; Fiorillo et al., 2003; Pan et al., 2005; Day et al., 2007; Roesch et al., 2007; Clark et al., 2010; Takahashi et al., 2011; Cohen et al., 2012). However, less attention has been paid to these signals in animals foraging for rewards in a seminaturalistic environment (Martig and Mizumori, 2011). In agreement with the previous finding that phasic DA activity shifts from the receipt of rewards to rewardpredicting stimuli during Pavlovian learning (Schultz et al., 1997; Pan et al., 2005; Day et al., 2007; Clark et al., 2010), DA cells in foraging rats showed a response transfer from after to before the acquisition of rewards across recording sessions. We initially expected that contextual stimuli around the maze might serve as reward-predicting cues, since rats should use them to discriminate the maze arms associated with large and small rewards and to perform the spatial working memory task. However, a prereward DA response was not observed around times when the spatial information from the extramaze stimuli were likely needed most (i.e., when rats chose one of the maze arms $\sim 1.5-2 \mathrm{~s}$ before reward acquisition). This indicated that the visual contextual stimuli were not reliably predictive of forthcoming rewards as these landmark cues sometimes led to the absence of reward in error choices. Instead, DA cells exhibited prereward responses

\section{$\leftarrow$}

(Figure legend continued.) conditions. The shaded regions indicate SEM. E, Three representative prereward DA cells in SAL and MUS sessions. MUS injections into the MPFC significantly decreased the prereward activity in the second block. $F$, Distributions of difference scores comparing prereward responses between blocks. G, Population PETHs of all prereward DA cells in SAL and MUS sessions. when rats were close enough to food cups to detect the presence of rewards. The fact that no such activity was evident in the absence of reward strongly suggests that the visual and/or olfactory information that directly emanated from chocolate milk may have been used as reward-predicting cues and triggered DA responses during spatial navigation. The finding of graded prereward responses with different amounts of reward is also in line with this view. Similarly, Schultz and his colleague (1990) reported that tactile sensation of a food reward elicited a phasic increase in DA activity when monkeys were required to find the reward in a covered box during self-initiated arm movements (Romo and Schultz, 1990). Together, these results indicate that sensory proximity (i.e., the sight, smell, and touch of a primary reward) plays a critical role in generating DAergic prediction error signals in animals foraging for food in a seminaturalistic environment.

Recent work showed that GABA cells in the VTA represent expected rewards after a reward-predicting cue was presented in a Pavlovian conditioning task (Cohen et al., 2012), and these cells play a critical role in reward consumption (van Zessen et al., 2012). It was unclear which non-DA cells were GABAergic in the current study because the waveform analysis was devised to classify DA cells in the VTA (Roesch et al., 2007; Takahashi et al., 2009, 2011; Jin and Costa, 2010;). Nonetheless, we found two types of non-DA responses in agreement with the proposed GABAergic functions (i.e., postreward activity for reward consumption and prereward activity for reward expectation). Specifically, postreward non-DA cells exhibited an increase in firing only during the period of reward consumption. Prereward non-DA activity occurred in expectation of upcoming rewards in rewarded choices. Consistent with the previous finding (Cohen et al., 2012), the prereward activity was also evident in unrewarded error choices, presumably because rats might be expected to obtain rewards as if they had never visited the chosen arms before. Available evidence suggests that the non-DA cells receive rewardresponsive inputs from the pedunculopontine tegmental nucleus (Okada et al., 2009; Norton et al., 2011) and reward expectation signals from various subregions of the PFC (Pratt and Mizumori, 2001; Miyazaki et al., 2004; Takahashi et al., 2009, 2011; Sul et al., 2010). Using the same behavioral task, our laboratory has reported that single neurons in the pedunculopontine tegmental nucleus exhibited reward responses similar to those of postreward non-DA cells (Norton et al., 2011), while mPFC neurons showed anticipatory responses similar to those of prereward non-DA cells (Pratt and Mizumori, 2001). Although a few mPFC cells responded after the acquisition of reward, none exhibited long-lasting responses during reward consumption like postreward non-DA cells. These segregated pathways that convey different reward-related information to the VTA may account for why mPFC dysfunction selectively altered the prereward, but not postreward, non-DA activity in the current study. Furthermore, the significant decrease in prereward non-DA activity after $\mathrm{mPFC}$ inactivation indicates that the $\mathrm{mPFC}$ may provide expectation about rewards to these cells during the spatial working memory task.

As the biggest sources of cortical glutamatergic projections, the mPFC directly synapses onto both DA and GABA neurons in the VTA (Carr and Sesack, 2000; Geisler and Wise, 2008). The anatomical findings account for the current results that mPFC inactivation induced significant decreases in spontaneous activity of both DA and non-DA cells as well as in prereward activity of non-DA cells, presumably due to the lack of glutamatergic inputs from the $\mathrm{mPFC}$. Interestingly, $\mathrm{mPFC}$ inactivation produced the 
opposite effect on phasic DA activity (i.e., a significant increase of DA responses to reward-predicting cues). This seems somewhat contradictory, but a large body of evidence indicates that the mPFC can exert an inhibitory influence on DA cells in the VTA. For example, electrophysiological studies found that electrical stimulation of the mPFC caused both excited and inhibited responses in separate groups of DA cells (Gariano and Groves, 1988; Overton et al., 1996; Tong et al., 1996; Lodge, 2011). A consensus among these studies is that the DA cells inhibited for several hundred milliseconds after mPFC stimulation outnumber the excited DA cells. Additionally, mPFC stimulation at physiologically relevant frequencies decreases extracellular DA transmission measured in the nucleus accumbens (Jackson et al., 2001). The inhibitory effect of the mPFC on DA cells is thought to be mediated by GABA cells in the VTA that synapse locally onto DA cells (Omelchenko and Sesack, 2009). Thus, it is possible that prereward DA cells may be disinhibited by the reduction in prereward non-DA activity after $\mathrm{mPFC}$ inactivation.

The elevated DA response to reward-predicting cues can also be accounted for by temporal difference reinforcement learning models (Montague et al., 1996; Schultz et al., 1997). The decreased prereward non-DA activity suggested that $\mathrm{mPFC}$-inactivated rats might have a significantly lower expectation of forthcoming rewards while approaching food cups. In this state, an unexpected encounter with reward-predicting sensory cues might have increased prereward activity of DA cells. This explanation also predicts that mPFC inactivation should lead to an increase in postreward DA activity. However, postreward responses in MUS sessions were not altered in the current study. Considering that DA cells exhibited postreward responses when rats did not fully learn which stimuli near the food cups predicted the presence of rewards, it is possible that the postreward DA activity in early recording sessions was similar to situations where the DA cells were responding to unexpected rewards. Thus, an additional loss of reward expectation after mPFC inactivation might not produce a significant change in postreward DA activity.

Exploring the neural mechanism of PFC-VTA interactions has significant implications for our understanding of the pathophysiology of DA-related disorders. In particular, a hypoactive PFC function is associated with elevated striatal DA transmission in schizophrenia (Weinberger, 1987; Davis et al., 1991; Grace, 2000; Meyer-Lindenberg et al., 2002), but the causal relationship between the two abnormalities remains unclear. The present study provides direct evidence that $\mathrm{mPFC}$ dysfunction can drive a hyperactivity of the DA system selectively when positively reinforcing events are expected, but not when rewarding events are experienced. The increased DA response to reward-predicting cues appears to be mediated by a reduction of inhibitory non-DA activity after mPFC dysfunction. These results imply that intact PFC function is necessary to regulate proper levels of DA activity in a situation where environmental cues associated with positive reinforcement are abundant (e.g., multiple decks of cards and the chime of coins in a casino). An abnormal regulation of DA activity by the MPFC may lead to the development of maladaptive behavior as seen in schizophrenic patients, such as impaired decision making and pathological gambling (Potenza and Chambers, 2001; Heerey et al., 2008).

\section{References}

Carr DB, Sesack SR (2000) Projections from the rat prefrontal cortex to the ventral tegmental area: target specificity in the synaptic associations with mesoaccumbens and mesocortical neurons. J Neurosci 20:3864-3873. Medline

Clark JJ, Sandberg SG, Wanat MJ, Gan JO, Horne EA, Hart AS, Akers CA, Parker JG, Willuhn I, Martinez V, Evans SB, Stella N, Phillips PE (2010)
Chronic microsensors for longitudinal, subsecond dopamine detection in behaving animals. Nat Methods 7:126-129. CrossRef Medline

Cohen JY, Haesler S, Vong L, Lowell BB, Uchida N (2012) Neuron-typespecific signals for reward and punishment in the ventral tegmental area. Nature 482:85-88. CrossRef Medline

Davis KL, Kahn RS, Ko G, Davidson M (1991) Dopamine in schizophrenia: a review and reconceptualization. Am J Psychiatry 148:1474-1486. Medline

Day JJ, Roitman MF, Wightman RM, Carelli RM (2007) Associative learning mediates dynamic shifts in dopamine signaling in the nucleus accumbens. Nat Neurosci 10:1020-1028. CrossRef Medline

Fields HL, Hjelmstad GO, Margolis EB, Nicola SM (2007) Ventral tegmental area neurons in learned appetitive behavior and positive reinforcement. Annu Rev Neurosci 30:289-316. CrossRef Medline

Fiorillo CD, Tobler PN, Schultz W (2003) Discrete coding of reward probability and uncertainty by dopamine neurons. Science 299:1898-1902. CrossRef Medline

Floresco SB, Seamans JK, Phillips AG (1997) Selective roles for hippocampal, prefrontal cortical, and ventral striatal circuits in radial-arm maze tasks with or without a delay. J Neurosci 17:1880-1890. Medline

Fuster JM (1997) The prefrontal cortex, third edition. New York: Raven.

Gariano RF, Groves PM (1988) Burst firing induced in midbrain dopamine neurons by stimulation of the medial prefrontal and anterior cingulate cortices. Brain Res 462:194-198. CrossRef Medline

Geisler S, Wise RA (2008) Functional implications of glutamatergic projections to the ventral tegmental area. Rev Neurosci 19:227-244. Medline

Goldman-Rakic PS (1995) Cellular basis of working memory. Neuron 14: 477-485. CrossRef Medline

Grace AA (2000) Gating of information flow within the limbic system and the pathophysiology of schizophrenia. Brain Res Brain Res Rev 31:330 341. CrossRef Medline

Grace AA, Bunney BS (1984) The control of firing pattern in nigral dopamine neurons: burst firing. J Neurosci 4:2877-2890. Medline

Heerey EA, Bell-Warren KR, Gold JM (2008) Decision-making impairments in the context of intact reward sensitivity in schizophrenia. Biol Psychiatry 64:62-69. CrossRef Medline

Jackson ME, Frost AS, Moghaddam B (2001) Stimulation of prefrontal cortex at physiologically relevant frequencies inhibits dopamine release in the nucleus accumbens. J Neurochem 78:920-923. CrossRef Medline

Jin X, Costa RM (2010) Start/stop signals emerge in nigrostriatal circuits during sequence learning. Nature 466:457-462. CrossRef Medline

Jo YS, Lee I (2010) Disconnection of the hippocampal-perirhinal cortical circuits severely disrupts object-place paired associative memory. J Neurosci 30:9850-9858. CrossRef Medline

Jo YS, Park EH, Kim IH, Park SK, Kim H, Kim HT, Choi JS (2007) The medial prefrontal cortex is involved in spatial memory retrieval under partial-cue conditions. J Neurosci 27:13567-13578. CrossRef Medline

Lodge DJ (2011) The medial prefrontal and orbitofrontal cortices differentially regulate dopamine system function. Neuropsychopharmacology 36 : 1227-1236. CrossRef Medline

Martig AK, Mizumori SJ (2011) Ventral tegmental area and substantia nigra neural correlates of spatial learning. Learn Mem 18:260-271. CrossRef Medline

Meyer-Lindenberg A, Miletich RS, Kohn PD, Esposito G, Carson RE, Quarantelli M, Weinberger DR, Berman KF (2002) Reduced prefrontal activity predicts exaggerated striatal dopaminergic function in schizophrenia. Nat Neurosci 5:267-271. CrossRef Medline

Miller EK, Cohen JD (2001) An integrative theory of prefrontal cortex function. Annu Rev Neurosci 24:167-202. CrossRef Medline

Miyazaki K, Miyazaki KW, Matsumoto G (2004) Different representation of forthcoming reward in nucleus accumbens and medial prefrontal cortex. Neuroreport 15:721-726. CrossRef Medline

Montague PR, Dayan P, Sejnowski TJ (1996) A framework for mesencephalic dopamine systems based on predictive Hebbian learning. J Neurosci 16:1936-1947. Medline

Norton AB, Jo YS, Clark EW, Taylor CA, Mizumori SJ (2011) Independent neural coding of reward and movement by pedunculopontine tegmental nucleus neurons in freely navigating rats. Eur J Neurosci 33:1885-1896. CrossRef Medline

Okada K, Toyama K, Inoue Y, Isa T, Kobayashi Y (2009) Different pedunculopontine tegmental neurons signal predicted and actual task rewards. J Neurosci 29:4858-4870. CrossRef Medline 
Omelchenko N, Sesack SR (2009) Ultrastructural analysis of local collaterals of rat ventral tegmental area neurons: GABA phenotype and synapses onto dopamine and GABA cells. Synapse 63:895-906. CrossRef Medline

Overton PG, Tong ZY, Clark D (1996) A pharmacological analysis of the burst events induced in midbrain dopaminergic neurons by electrical stimulation of the prefrontal cortex in the rat. J Neural Transm 103:523540. CrossRef Medline

Pan WX, Hyland BI (2005) Pedunculopontine tegmental nucleus controls conditioned responses of midbrain dopamine neurons in behaving rats. J Neurosci 25:4725-4732. CrossRef Medline

Pan WX, Schmidt R, Wickens JR, Hyland BI (2005) Dopamine cells respond to predicted events during classical conditioning: evidence for eligibility traces in the reward-learning network. J Neurosci 25:6235-6242. CrossRef Medline

Potenza MN, Chambers RA (2001) Schizophrenia and pathological gambling. Am J Psychiatry 158:497-498. CrossRef Medline

Pratt WE, Mizumori SJ (2001) Neurons in rat medial prefrontal cortex show anticipatory rate changes to predictable differential rewards in a spatial memory task. Behav Brain Res 123:165-183. CrossRef Medline

Puryear CB, Kim MJ, Mizumori SJ (2010) Conjunctive encoding of movement and reward by ventral tegmental area neurons in the freely navigating rodent. Behav Neurosci 124:234-247. CrossRef Medline

Roesch MR, Calu DJ, Schoenbaum G (2007) Dopamine neurons encode the better option in rats deciding between differently delayed or sized rewards. Nat Neurosci 10:1615-1624. CrossRef Medline

Romo R, Schultz W (1990) Dopamine neurons of the monkey midbrain: contingencies of responses to active touch during self-initiated arm movements. J Neurophysiol 63:592-606. Medline

Schultz W, Dayan P, Montague PR (1997) A neural substrate of prediction and reward. Science 275:1593-1599. CrossRef Medline

Seamans JK, Floresco SB, Phillips AG (1995) Functional differences between the prelimbic and anterior cingulate regions of the rat prefrontal cortex. Behav Neurosci 109:1063-1073. CrossRef Medline

Sesack SR, Pickel VM (1992) Prefrontal cortical efferents in the rat synapse on unlabeled neuronal targets of catecholamine terminals in the nucleus accumbens septi and on dopamine neurons in the ventral tegmental area. J Comp Neurol 320:145-160. CrossRef Medline

Sul JH, Kim H, Huh N, Lee D, Jung MW (2010) Distinct roles of rodent orbitofrontal and medial prefrontal cortex in decision making. Neuron 66:449-460. CrossRef Medline

Takahashi YK, Roesch MR, Stalnaker TA, Haney RZ, Calu DJ, Taylor AR, Burke KA, Schoenbaum G (2009) The orbitofrontal cortex and ventral tegmental area are necessary for learning from unexpected outcomes. Neuron 62:269-280. CrossRef Medline

Takahashi YK, Roesch MR, Wilson RC, Toreson K, O’Donnell P, Niv Y, Schoenbaum G (2011) Expectancy-related changes in firing of dopamine neurons depend on orbitofrontal cortex. Nat Neurosci 14: 1590-1597. CrossRef Medline

Taylor CL, Latimer MP, Winn P (2003) Impaired delayed spatial win-shift behaviour on the eight arm radial maze following excitotoxic lesions of the medial prefrontal cortex in the rat. Behav Brain Res 147:107-114. CrossRef Medline

Tong ZY, Overton PG, Clark D (1996) Stimulation of the prefrontal cortex in the rat induces patterns of activity in midbrain dopaminergic neurons which resemble natural burst events. Synapse 22:195-208. CrossRef Medline

van Zessen R, Phillips JL, Budygin EA, Stuber GD (2012) Activation of VTA GABA neurons disrupts reward consumption. Neuron 73:1184-1194. CrossRef Medline

Wang DV, Tsien JZ (2011) Conjunctive processing of locomotor signals by the ventral tegmental area neuronal population. PLoS One 6:e16528. CrossRef Medline

Weinberger DR (1987) Implications of normal brain development for the pathogenesis of schizophrenia. Arch Gen Psychiatry 44:660-669. CrossRef Medline

Wise RA (2004) Dopamine, learning and motivation. Nat Rev Neurosci 5:483-494. CrossRef Medline 